\title{
The Fisher Effect in the Presence of Time-Varying Coefficients
}

\begin{abstract}
A resolution of the Fisher effect puzzle in terms of statistical inference is attempted. Motivation stems from empirical evidence of time-varying coefficients in the data generating process of both the interest rates and inflation rates for 19 OECD countries. These time-varying dynamics crucially affect the behaviour of all the co-integration estimators considered, especially in small samples. When employing simulated critical values instead of asymptotic ones, the results provide ample evidence supporting the existence of a long-run Fisher effect in which interest rates move one-to-one with inflation rates in all countries under scrutiny except for Ireland and Switzerland.
\end{abstract}

Keywords: Co-integration Estimators; Fisher Effect; Monte Carlo Simulations; Time-varying Coefficients. 


\section{Introduction}

A vast literature is devoted to the size of the response of nominal interest rates to changes in expected inflation, broadly known as the Fisher (1930) effect (see Cooray, 2003). The importance of this response stems from the fact that permanent shocks to either inflation or nominal rates should not be translated into permanent disturbances to real rates themselves. Such a case would be problematic in the context of standard models of inter-temporal asset pricing. Moreover, long-run super-neutrality of money is associated with a coefficient relating interest rates to expected inflation equal to one. A value below unity implies substantial long-run non-neutralities.

Unfortunately, there is no consensus among economists about the true size of the Fisher effect, as several problems plague the empirical estimates. First, as Darby (1975) argued, the Fisher effect estimate should be greater than one in order to compensate debt holders for a lower after-tax return, since interest income is usually taxed as ordinary income. Second, the expected inflation rate is generally unobservable and when actual realised inflation is used to proxy expected inflation, an errors-in-variables bias is introduced on the estimate of the Fisher effect. Finally and more importantly, the time series properties of both interest rates and inflation rates should be considered carefully. In the event of integrated variables, the only way to establish a theoretical Fisher relationship is via co-integration techniques. However, even when applying the appropriate co-integration methods, severe problems may arise, such as the low power of co-integration tests, structural breaks and nonlinearities in the co-integrating relationship, or the performance of co-integration estimators in small samples.

In general, there is much conflicting evidence in the literature about the Fisher effect. Numerous studies have found that the slope coefficient in a regression of inflation against nominal rates is significantly different from 1, at least over certain periods. Mishkin (1992) was one of the first to suggest that the Fisher relation should be treated within the context of a cointegrated system, as in Engle and Granger (1987), but did not derive any strong conclusions due to the large standard errors of the estimated parameters. Subsequent studies used more efficient estimation procedures and generally found support for a long-run Fisher relation in the US (see Evans and Lewis, 1995; Crowder and Hoffman, 1996; Atkins and Coe, 2002; Fahmy and Kandil, 2003). Caporale and Pittis (2004) showed that the inability of the frequently employed estimators to provide efficient estimates in small samples is likely to be responsible for the over-rejection of the Fisher hypothesis. Once the estimators with the best properties are chosen, the evidence is strongly supportive of the Fisher effect in the US.

Turning to studies examining whether the Fisher relationship holds internationally, Rose (1988) examined the integration properties of nominal interest rates and inflation for 18 OECD countries. The author concluded that inflation does not appear to have a unit root, while nominal interest rates do. By contrast, Koustas and Serletis (1999) established that the Fisher effect conditions hold for a set of 10 industrialised countries, without, however, establishing a unit coefficient. With the development of panel co-integration techniques, several authors examined the international Fisher effect in a panel setting. For example, developing two new 
panel co-integration tests for the null of no co-integration, Westerlund (2008) showed that the null can be safely rejected for a panel of 20 OECD countries. The author provided evidence of a unit slope on inflation, thus lending support to an international Fisher effect. Moreover, Coakley et al. (2006), motivated by panel data studies on the Fisher and other economic relationships, provided insights into the impact of error cross-section dependence and persistent autocorrelation on panel regression estimates.

Another strand of the literature, developed relatively recently, takes another route and attempts to explain the failure of the Fisher effect due to either nonlinearities or structural breaks which may exist in this equilibrium relationship. Bierens (2000) and Lanne (2006) found that interest rates and inflation shared common nonlinear trends. Similar evidence was provided by Kapetanios et al. (2003) and Koustas and Lamarche (2010) who found that the process of the real interest rate exhibited asymmetric mean reversion, while stationary. Christopoulos and Leon-Ledesma (2007) showed that the co-integrating relationship between US interest rates and inflation was a nonlinear one. The authors attribute the less-than-proportional relationship found in the literature to this nonlinearity. On the other hand, Haug et al. (2011) provided evidence in favour of a linear Fisher relationship when accounting for structural breaks in the co-integration equation. However, in the majority of cases, their findings could not support the assumption that nominal interest rates and inflation move one-to-one in the long run.

In this study, we also focus on the empirical examination of the long-run Fisher effect for 19 OECD countries. Our main objective is to investigate whether the empirical failure of the Fisher effect is linked to the likely distorted small-sample performance of the co-integration estimators under time-varying dynamics. Previous studies that introduced time-varying dynamics in the analysis of co-integrated variables include Bierens and Martins (2010) and Koop et al. (2011). Both studies developed a vector error correction model which allows the co-integration relationship to evolve over time. Our approach differs since, under our data generating process (DGP), the coefficient of the co-integration equation is time invariant, while the time-varying dynamics are introduced in the process of the co-integrating error and the error that drives the regressor.

Our analysis is motivated by the potential of relevant shifts in policy conduct. Specifically, changes in monetary policy regimes are likely to be an important source of variation in the processes governing both real interest rates and inflation rates. In a similar mode, Haug et al. (2011) allowed for a time-varying co-integrating coefficient subject to breaks, probably induced by shifts in monetary policy stance. However, instead of allowing for abrupt regime changes, our error model parameters shift over time in a smooth and gradual fashion consistent with interest-rate smoothing monetary policy. Trecroci and Vassalli (2010) modelled monetary policy reaction functions with a time-varying parameter model and provided an extensive discussion on its appropriateness.

We put forward a wide class of processes, which allow for more general heterogeneity properties in the data similar to those encountered in empirical applications. Specifically, we model the co-integrating error process and the error that drives the inflation process as a vector au- 
toregressive model with either autoregressive or random coefficients. Interestingly, this class of DGPs is likely to satisfy the conditions for the applicability of the functional central limit theorem (FCLT), thus allowing for asymptotics of integrated processes to be derived and restoring the asymptotic optimality of the common co-integration estimators (Phillips and Durlauf, 1986). The behaviour of various co-integration estimators in the presence of time-varying coefficients is then examined. By means of Monte Carlo simulations, we show that these time-varying dynamics affect the behaviour of all the co-integration estimators considered in this study, causing significant size distortions when testing the Fisher effect. Our findings suggest that among the estimators under scrutiny, the augmented autoregressive distributed lag (AADL) estimator (Pesaran and Shin, 1999) appears to be the most robust estimator to time-varying dynamics, closely followed by the fully modified least squares (FMLS) estimator (Phillips and Hansen, 1990).

As a second step in our analysis, we estimate the Fisher equation and base our statistical tests on simulated critical values instead of asymptotic ones. Taking this route, we find that the Fisher effect survives the empirical evidence irrespective of the estimator choice, with just a few exceptions. We, therefore, conjecture that a possible explanation for the scarce evidence of an international Fisher effect in the literature is the poor small-sample performance of the co-integration estimators under a DGP with time-varying coefficients. A word of caution is in order here. Our findings do not rule out the possibility of alternative specifications, such as regime switching or breaks in either the error dynamics or the co-integration parameter.

The layout of this paper is as follows: Section 2 provides a discussion of the Fisher equation and introduces the DGP for the relationship between interest rates and inflation. Next, we examine the effect of time-varying dynamics on the behaviour of various co-integration estimators. Section 3 presents the estimates of the Fisher equation obtained by various estimators and discusses the main findings of our empirical analysis. Finally, Section 4 summarises the main findings of the paper.

\section{Econometric methodology}

In this section, we first describe the Fisher effect modelling in a co-integrating framework and then introduce a DGP for the relationship between interest rates and inflation rates that allows for time-varying dynamics in the error generating process. We also provide some theoretical results on the presence of nuisance parameters in the distribution of the OLS estimator in the context of the DGP under consideration. Finally, we examine the behaviour of various co-integration estimators in terms of their ability to provide correct statistical inference in the presence of time-varying dynamics.

\subsection{Fisher effect modelling}

Formally, the 'Fisher effect' can be expressed as follows:

$$
i_{t}(m)=\pi_{t}^{e}(m)+r_{t}^{e}(m)
$$


where $i_{t}(m)$ is the m-period nominal interest rate at time t, $\pi_{t}^{e}(m)$ denotes the expected rate of inflation from time $\mathrm{t}$ to $\mathrm{t}+\mathrm{m}$, and $r_{t}^{e}(m)$ is the ex-ante real interest rate. Assuming rational expectations (see, for example, Mishkin, 1992), realised inflation is linked to expected inflation as follows:

$$
\pi_{t}(m)=\pi_{t}^{e}(m)+e_{t}
$$

where $e_{t}$ is a white noise process, orthogonal to $\pi_{t}^{e}(m)$. If we further assume that the process followed by the real interest rate is a white noise process with a mean equal to $r$, we are able to test for the Fisher effect in the context of the following regression:

$$
i_{t}(m)=r+\theta \pi_{t}(m)+\nu_{t} .
$$

If $i_{t}(m)$ and $\pi_{t}(m)$ are both considered to be I(1), the null hypothesis to be tested can take the following form:

Fisher hypothesis holds $\Leftrightarrow$ (i) $\nu_{t}$ is $\mathrm{I}(0)$ and (ii) $\theta=1$.

The first of these conditions, that is, the condition that $i_{t}(m)$ and $\pi_{t}(m)$ are co-integrated processes is supported by the bulk of empirical evidence in the literature. On the other hand, when dealing with the second condition, estimates of $\theta$ appear to be significantly different from unity, leading to the Fisher effect puzzle.

\subsection{The data generating process}

Many studies in the literature examine the co-integration equation between the variables of interest in the context of the triangular DGP proposed by Phillips (1988). Under this triangular DGP, the vector of the co-integrating error and the error that drives the regressor is usually modelled as a VAR(1) process. The need to parameterise the vector of errors stems from the necessity to evaluate the various estimators in finite samples, typically used in empirical applications, and/or to derive sample-specific critical values for testing a co-integration relationship of interest. In this context, several Monte Carlo studies of the small-sample properties of cointegration estimators have been conducted (see, for example, Phillips and Hansen, 1990; Stock and Watson, 1993; Christou and Pittis, 2002; and Panopoulou and Pittis, 2004).

In order to accommodate the empirical regularities observed in the relation between interest rates and inflation rates, we choose to introduce a more general DGP that allows for time-varying dynamics in the process of the co-integrating error and the error that drives the regressor. Specifically, we consider the following bivariate DGP for the $\mathrm{I}(1)$ vector $\mathbf{z}_{t}=\left[y_{t}, x_{t}\right]^{\top}$ :

$$
y_{t}=\theta x_{t}+u_{1 t}
$$

and

$$
\Delta x_{t}=u_{2 t} .
$$


We further assume that $\mathbf{u}_{t}=\left[u_{1 t}, u_{2 t}\right]^{\top}$ is an $\mathrm{I}(0)$ process generated as follows:

$$
u_{t}=\left(M+P_{t}\right) u_{t-1}+e_{t},
$$

where $M$ is a diagonal $2 \times 2$ parameter matrix and $P_{t}$ is a diagonal $2 \times 2$ time-varying matrix. Specifically,

$$
\left(\begin{array}{l}
u_{1 t} \\
u_{2 t}
\end{array}\right)=\left[\left(\begin{array}{ll}
\mu_{11} & 0 \\
0 & \mu_{22}
\end{array}\right)+\left(\begin{array}{ll}
\rho_{11, t} & 0 \\
0 & \rho_{22, t}
\end{array}\right)\right]\left(\begin{array}{l}
u_{1 t-1} \\
u_{2 t-1}
\end{array}\right)+\left(\begin{array}{l}
e_{1 t} \\
e_{2 t}
\end{array}\right)
$$

and

$$
\left(\begin{array}{l}
e_{1 t} \\
e_{2 t}
\end{array}\right) \sim \operatorname{NIID}\left[\left(\begin{array}{l}
0 \\
0
\end{array}\right), \Sigma_{12}=\left(\begin{array}{ll}
\sigma_{11} & \sigma_{12} \\
\sigma_{12} & \sigma_{22}
\end{array}\right)\right] .
$$

Moreover, we allow $P_{t}$ to follow a vector autoregressive (VAR) process of order 1 , that is, $P_{t}=\Phi P_{t-1}+v_{t}$, where $\Phi$ is a diagonal $2 \times 2$ constant parameter matrix:

$$
\left(\begin{array}{l}
\rho_{11, t} \\
\rho_{22, t}
\end{array}\right)=\left(\begin{array}{ll}
\phi_{11} & 0 \\
0 & \phi_{22}
\end{array}\right)\left(\begin{array}{l}
\rho_{11, t-1} \\
\rho_{22, t-1}
\end{array}\right)+\left(\begin{array}{l}
v_{1 t} \\
v_{2 t}
\end{array}\right)
$$

and

$$
\left(\begin{array}{l}
v_{1 t} \\
v_{2 t}
\end{array}\right) \sim \operatorname{NIID}\left[\left(\begin{array}{l}
0 \\
0
\end{array}\right), \Sigma_{34}=\left(\begin{array}{ll}
\sigma_{33} & 0 \\
0 & \sigma_{44}
\end{array}\right)\right] .
$$

It is easy to see that under this specification, the co-integration error and the error that drives the regressor follow the following two univariate processes:

$$
u_{1 t}=\left(\mu_{11}+\rho_{11, t}\right) u_{1 t-1}+e_{1 t}, \rho_{11, t}=\phi_{11} \rho_{11, t-1}+v_{1 t}
$$

and

$$
u_{2 t}=\left(\mu_{22}+\rho_{22, t}\right) u_{2 t-1}+e_{2 t}, \rho_{22, t}=\phi_{22} \rho_{22, t-1}+v_{2 t} .
$$

Appendix A1 provides the stationarity condition for $u_{1 t}$ and $u_{2 t}$ based on the results of Weiss (1985).

The aforementioned DGP assumes that $\mathbf{u}_{t}$ follows a VAR(1) model with AR(1) coefficients (VAR(1)-AR(1) process). In our analysis, we also consider a second DGP that assumes that $\mathbf{u}_{t}$ follows a $\operatorname{VAR}(1)$ process with random coefficients (VAR(1)-RC process). This case is naturally a subset of the previous one. By setting $\Phi=0, P_{t}$ is a mean zero process with $E\left[P_{t} \otimes P_{t}\right]=C$. It is easy to show that the elements of the matrix $C$ can be obtained from those of the matrix $\Sigma_{34}$ for a diagonal matrix $P_{t}$. In deriving the necessary and sufficient conditions for the stationarity and stability of this process, we further assume that $P_{t}$ is independent of $e_{t}$. Analytically, the generating mechanism for the $\operatorname{VAR}(1)-\mathrm{RC}$ case is given by the following equations:

$$
\left(\begin{array}{l}
u_{1 t} \\
u_{2 t}
\end{array}\right)=\left[\left(\begin{array}{cc}
\mu_{11} & 0 \\
0 & \mu_{22}
\end{array}\right)+\left(\begin{array}{cc}
\rho_{11, t} & 0 \\
0 & \rho_{22, t}
\end{array}\right)\right]\left(\begin{array}{l}
u_{1 t-1} \\
u_{2 t-1}
\end{array}\right)+\left(\begin{array}{l}
e_{1 t} \\
e_{2 t}
\end{array}\right)
$$


and

$$
\left(\begin{array}{c}
e_{1 t} \\
e_{2 t} \\
\rho_{11, t} \\
\rho_{22, t}
\end{array}\right) \sim N I I D\left[\left(\begin{array}{l}
0 \\
0 \\
0 \\
0
\end{array}\right),\left(\begin{array}{cccc}
\sigma_{11} & \sigma_{12} & 0 & 0 \\
\sigma_{12} & \sigma_{22} & 0 & 0 \\
0 & 0 & \sigma_{33} & 0 \\
0 & 0 & 0 & \sigma_{44}
\end{array}\right)\right] .
$$

After some algebra, we show that the stationarity of the $\operatorname{VAR}(1)$-RC model is ensured by the following condition.

Proposition 1 The vector $\mathbf{u}_{t}=\left[u_{1 t}, u_{2 t}\right]^{\top}$ that follows a VAR(1)-RC process given by equations (9) and (10) is stationary if $1-\mu_{11}^{2}-\sigma_{33}>0$ and $1-\mu_{22}^{2}-\sigma_{44}>0$.

Proof. See Appendix A2.

Next, we relate the parameters of our DGPs to the nuisance parameters that are present in the distribution of the OLS estimator.

\subsection{Nuisance parameters}

The presence of nuisance parameters in the distribution of the OLS estimator renders standard asymptotic theory useless in the case of co-integration. The reason for the presence of these nonstandard asymptotics is that when the elements of $\mathbf{u}_{t}$ are contemporaneously and/or temporally correlated, the following two types of second-order asymptotic effects are present in the limiting distribution of the OLS estimator (see Phillips and Loretan, 1991): (i) The nuisance parameter $\omega_{12} / \omega_{22}$ that describes the 'long-run correlation' effect, due to non-diagonality of the long-run covariance matrix $\Omega=\left[\omega_{i j}\right], i, j=1,2$ and (ii) The nuisance parameter $\delta_{21}=\sum_{k=0}^{\infty} E\left(u_{20} u_{1 k}\right)$ (of the one-sided covariance matrix, $\Delta$ ) that describes the 'endogeneity' effect. However, the design of our DGPs rules out any feedbacks from the co-integration error to the error that drives the regressor or from the regressor to the error that drives the co-integration error. In this case, both nuisance parameters have the same source, namely, the contemporaneous correlation between $u_{1 t}$ and $u_{2 t}$.

We now derive the relevant nuisance parameters for the VAR(1)-RC process given by equations (9) and (10). To keep the analysis clear, the derivation of the variance matrices is given in Appendix B. We end up with the following formulas: The variance-covariance matrix $V$ of $\mathbf{u}_{t}$ is given by

$$
v e c V=(I-M \otimes M-C)^{-1} v e c \Sigma_{12}
$$

and the long-run covariance matrix $\Omega$ is given by

$$
\Omega=V+M(I-M)^{-1} V+V\left(I-M^{\prime}\right)^{-1} M^{\prime}
$$

In our DGP,

$$
\Omega=\left(\begin{array}{cc}
\frac{\left(1+\mu_{11}\right) \sigma_{11}}{\left(1-\mu_{11}\right)\left(1-\mu_{11}^{2}-\sigma_{33}\right)} & \frac{\sigma_{12}}{\left(1-\mu_{11}\right)\left(1-\mu_{22}\right)} \\
\frac{\sigma_{12}}{\left(1-\mu_{11}\right)\left(1-\mu_{22}\right)} & \frac{\left(1+\mu_{22}\right) \sigma_{22}}{\left(1-\mu_{22}\right)\left(1-\mu_{22}^{2}-\sigma_{44}\right)}
\end{array}\right)
$$


and

$$
\Delta=\left(\begin{array}{cc}
\frac{\sigma_{11}}{\left(1-\mu_{11}\right)\left(1-\mu_{11}^{2}-\sigma_{33}\right)} & \frac{\sigma_{12}}{\left(1-\mu_{11}\right)\left(1-\mu_{11} \mu_{22}\right)} \\
\frac{\sigma_{12}}{\left(1-\mu_{22}\right)\left(1-\mu_{11} \mu_{22}\right)} & \frac{\sigma_{22}}{\left(1-\mu_{22}\right)\left(1-\mu_{22}^{2}-\sigma_{44}\right)}
\end{array}\right)
$$

Hence, we have

$$
\frac{\omega_{12}}{\omega_{22}}=\frac{\sigma_{12}\left(1-\mu_{22}^{2}-\sigma_{44}\right)}{\left(1-\mu_{11}\right)\left(1+\mu_{22}\right) \sigma_{22}}
$$

and

$$
\delta_{21}=\frac{\sigma_{12}}{\left(1-\mu_{22}\right)\left(1-\mu_{11} \mu_{22}\right)} .
$$

We observe that both nuisance parameters are increasing functions of $\mu_{11}$ and $\sigma_{12}$. On the other hand, the persistence of the error that drives the regressor (mainly controlled by $\mu_{22}$ ) drives the nuisance parameters in the opposite direction; that is, as $\mu_{22}$ increases, $\frac{\omega_{12}}{\omega_{22}}$ decreases while $\delta_{21}$ increases. What is interesting in this case is that the effect of the random coefficients does not amplify the magnitude of the nuisance parameters. Specifically, as $\sigma_{44}$ increases, the 'long-run correlation' effect decreases, due to increased variation in the error that drives the regressor.

Similar results for the general case of a $\operatorname{VAR}(1)$-AR(1) process are not easy to derive, due to the algebraic intractability of the process.

\subsection{Monte Carlo simulations}

We investigate, by means of Monte Carlo simulations, the finite sample performance of various co-integration estimators in cases where the co-integration error and the error that drives the regressor follow either a $\operatorname{VAR}(1)-\mathrm{AR}(1)$ or a $\operatorname{VAR}(1)$-RC process. The estimators are evaluated on the basis of their accuracy of statistical inference since this is of interest in our empirical investigation of the Fisher effect. As a measure of accuracy of statistical inference, we calculate the empirical size of the t-test for testing the hypothesis $\theta=1$ in equation (2) for a nominal size of $5 \%$. We use 2000 replications and consider sample sizes of $T+50$ observations with $T$ equal to 50,150 , and 200. In all cases, the first 50 observations are discarded to eliminate the effect of initial values. The selected sample sizes are in line with the sample sizes of most empirical applications, including the one presented in Section 3 of this study.

We consider the following nine estimators: (i) the standard OLS estimator; (ii) two versions of the DOLS estimator - one, denoted as DOLS(hac), uses the HAC covariance matrix estimator while the other, denoted as DOLS, re-scales the OLS coefficient covariance matrix; (iii) two versions of the canonical cointegrating regression (CCR) estimator, denoted as CCR(nw) and CCR(a); (iv) two versions of the FMLS estimator, denoted as FMLS(nw) and FMLS(a), which use either the Newey-West or the Andrews procedure for bandwidth selection, respectively; (v) the JOH estimator; and (vi) the AADL estimator. We use the Akaike information criterion (AIC) to choose the lag and lead specification for DOLS and AADL along with the lag specification for $\mathrm{JOH}$. AIC is also used to determine the optimal lag specification for the estimation of the long-run covariance matrix in the context of FMLS and CCR. Appendix C provides a brief description of these estimators.

We generate random samples from DGPs that are similar, but differ in the value of only 
one or two coefficients, in order to be able to isolate the effect of each coefficient of interest on the behaviour of the estimators under scrutiny. In the case of a VAR(1)-RC process, the coefficients that affect the nuisance parameters and, as a consequence, the behaviour of the estimators are $\sigma_{12}, \sigma_{44}$, and $\mu_{11}$. Moreover, when we consider the case of a $\operatorname{VAR}(1)-\operatorname{AR}(1)$ process, the values of $\phi_{11}$ and $\phi_{22}$ probably affect the results. On the other hand, we keep the value of all the remaining coefficients of the DGP fixed throughout the experiment. Specifically, we set $\sigma_{11}=\sigma_{22}=1, \mu_{22}=0.3$, and $\sigma_{33}=0.1$.

Our first experiment focuses on the case of a VAR(1)-RC process. Specifically, we examine six different DGPs, and the results for samples of 50, 150, and 200 observations are reported in Table 1. The first DGP (DGP1) corresponds to a process with (i) small contemporaneous correlation between $u_{1 t}$ and $u_{2 t}\left(\sigma_{12}=0.3\right)$, (ii) low persistence of $u_{1 t}\left(\mu_{11}=0.4\right)$, and (iii) mild time-varying dynamics $\left(\sigma_{44}=0.1\right)$. DGP1 serves as a benchmark in our analysis since it describes a process with mild time-varying dynamics and small nuisance parameters. Even though DGP1 is a process with relatively mild dynamics, we observe significant size distortions especially for small samples of 50 observations. To be more specific, when $T=50$, both versions of the DOLS estimator have an empirical size of around 30\%, which is much higher than the nominal size of 5\%. Similarly, the empirical size of the OLS and JOH estimators is around 20\%, while AADL appears to be the estimator with the lowest size distortions, with an empirical size of $12 \%$.

As the sample size increases, the behaviour of all estimators improves. When $T=150$, most estimators have an empirical size that ranges from 7\% (AADL, FMLS(a), and CCR(a)) to 9\% (JOH). The empirical size of DOLS(hac) also decreases from $29 \%$ to $13 \%$. On the other hand, the 'naive' versions of DOLS and OLS continue to have important size distortions with empirical sizes of $22 \%$ and $18 \%$, respectively. If we further increase the sample size to 200 observations, the behaviour of DOLS and OLS does not improve, while the size distortions for the remaining estimators slightly decrease.

The comparison of the results for DGP1 and DGP2 shows that the size of the contemporaneous correlation between $u_{1 t}$ and $u_{2 t}$ seems to lead to a small increase in the size distortions of OLS, while the behaviour of the other estimators remains unaffected. Comparing DGP3 and DGP5, we find that when the persistence of $u_{1 t}$ is relatively high, an increase in $\sigma_{12}$ increases the size distortions of both versions of the CCR estimator, especially for small sample sizes. Moreover, high persistence of the co-integration error $u_{1 t}$ leads to a significant deterioration of the behaviour of all estimators. For example, when we increase $\mu_{11}$ to 0.7 (DGP3), the empirical size of DOLS and $\mathrm{JOH}$ is $54 \%$ and $30 \%$, respectively $(T=50)$. AADL seems to be the estimator that is less affected by the persistence of $u_{1 t}$ since its empirical size increases from $12 \%$ in DGP1 to $15 \%$ in DGP3 $(T=50)$. The behaviour of all estimators improves as the sample size increases and most estimators have an empirical size of around $10 \%$ when $T=150$, which further decreases to $7 \%$ to $9 \%$ when $T=200$. OLS, DOLS, and, to a lesser degree, DOLS(hac) are the only exceptions with much higher size distortions compared to the other estimators considered in this study. Finally, an increase in the value of $\sigma_{44}$ that controls the 
Table 1: Empirical size for the Fisher hypothesis (VAR(1)-RC model)

\begin{tabular}{|c|c|c|c|c|c|c|}
\hline & "DGP1 & 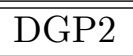 & DGP3 & DGP4 & DGP5 & $\overline{\text { DGP6 }}$ \\
\hline$\sigma_{12}$ & 0.3 & 0.9 & 0.3 & 0.3 & 0.9 & 0.9 \\
\hline$\sigma_{44}$ & 0.1 & 0.1 & 0.1 & 0.4 & 0.1 & 0.4 \\
\hline$\mu_{11}$ & 0.4 & 0.4 & 0.7 & 0.4 & 0.7 & 0.7 \\
\hline Panel A & \multicolumn{6}{|c|}{$\mathrm{T}=50$} \\
\hline OLS & 0.21 & 0.26 & 0.41 & 0.19 & 0.56 & 0.51 \\
\hline DOLS(hac) & 0.29 & 0.28 & 0.42 & 0.29 & 0.44 & 0.44 \\
\hline DOLS & 0.30 & 0.29 & 0.54 & 0.29 & 0.53 & 0.54 \\
\hline FMLS(nw) & 0.16 & 0.16 & 0.21 & 0.15 & 0.22 & 0.23 \\
\hline FMLS(a) & 0.14 & 0.14 & 0.20 & 0.13 & 0.21 & 0.22 \\
\hline $\operatorname{CCR}(\mathrm{nw})$ & 0.17 & 0.16 & 0.22 & 0.17 & 0.28 & 0.26 \\
\hline $\operatorname{CCR}(\mathrm{a})$ & 0.15 & 0.15 & 0.22 & 0.15 & 0.29 & 0.26 \\
\hline $\mathrm{JOH}$ & 0.19 & 0.18 & 0.30 & 0.18 & 0.26 & 0.30 \\
\hline AADL & 0.12 & 0.12 & 0.15 & 0.12 & 0.16 & 0.16 \\
\hline Panel B & \multicolumn{6}{|c|}{$\mathrm{T}=150$} \\
\hline OLS & 0.18 & 0.26 & 0.38 & 0.20 & 0.57 & 0.49 \\
\hline DOLS(hac) & 0.13 & 0.14 & 0.19 & 0.14 & 0.21 & 0.24 \\
\hline DOLS & 0.22 & 0.22 & 0.44 & 0.22 & 0.45 & 0.47 \\
\hline FMLS(nw) & 0.08 & 0.08 & 0.10 & 0.09 & 0.10 & 0.12 \\
\hline FMLS(a) & 0.07 & 0.07 & 0.10 & 0.09 & 0.09 & 0.12 \\
\hline CCR(nw) & 0.08 & 0.08 & 0.10 & 0.09 & 0.14 & 0.14 \\
\hline $\operatorname{CCR}(\mathrm{a})$ & 0.07 & 0.08 & 0.10 & 0.09 & 0.14 & 0.14 \\
\hline $\mathrm{JOH}$ & 0.09 & 0.09 & 0.12 & 0.09 & 0.11 & 0.13 \\
\hline AADL & 0.07 & 0.08 & 0.09 & 0.07 & 0.09 & 0.10 \\
\hline Panel C & \multicolumn{6}{|c|}{$\mathrm{T}=200$} \\
\hline OLS & 0.19 & 0.28 & 0.40 & 0.19 & 0.58 & 0.53 \\
\hline DOLS(hac) & 0.11 & 0.12 & 0.17 & 0.12 & 0.18 & 0.17 \\
\hline DOLS & 0.22 & 0.22 & 0.43 & 0.22 & 0.45 & 0.43 \\
\hline FMOLS(nw) & 0.07 & 0.07 & 0.09 & 0.07 & 0.09 & 0.08 \\
\hline FMOLS(a) & 0.06 & 0.06 & 0.08 & 0.06 & 0.09 & 0.09 \\
\hline $\mathrm{CCR}(\mathrm{nw})$ & 0.07 & 0.08 & 0.09 & 0.07 & 0.11 & 0.10 \\
\hline $\mathrm{CCR}(\mathrm{a})$ & 0.07 & 0.07 & 0.08 & 0.07 & 0.11 & 0.10 \\
\hline $\mathrm{JOH}$ & 0.07 & 0.08 & 0.09 & 0.07 & 0.09 & 0.09 \\
\hline AADL & 0.06 & 0.07 & 0.07 & 0.06 & 0.08 & 0.07 \\
\hline
\end{tabular}

Notes: The DGP is given by equations (2)-(3) and (9)-(10). 
'random-coefficient' effect (together with $\sigma_{33}$ ) causes, in general, minor improvements in the behaviour of the estimators. This is illustrated by the comparison of DGP4 to either DGP1 or DGP6.

In summary, the findings of our first Monte Carlo experiment suggest that all the estimators under scrutiny suffer from size distortions when the DGP corresponds to a VAR(1)-RC process. The size distortions are higher for small sample sizes and are an increasing function of the persistence of the co-integration error and, to a lesser degree, of the contemporaneous correlation between $u_{1 t}$ and $u_{2 t}$. AADL appears to be the best-performing estimator followed by the two versions of FMLS. On the other hand, OLS and DOLS are the estimators with the worst behaviour in the context of our DGPs.

Our second experiment focuses on the case of a VAR(1)-AR(1) process. We consider four different DGPs: DGP7 to DGP10. The results, reported in Table 2 along with the results for DGP1, which serves as a benchmark, suggest that switching from a VAR(1)-RC process to a VAR(1)-AR(1) process increases the size distortions of all the estimators examined in our analysis. In all cases, the size distortions decrease as the sample size increases. AADL remains the best-performing estimator, closely followed by FMLS and CCR. On the other hand, OLS and DOLS have the largest size distortions among the estimators under scrutiny. The comparison of the empirical sizes for DGP7 and DGP8 shows that high values of $\mu_{11}$ cause larger size distortions compared to high values of $\phi_{11}$. DGP9 reveals that, similar to the VAR(1)-RC case, the size distortions increase with the size of $\sigma_{12}$. Finally, DGP10 shows that the behaviour of the estimators is not affected by the value of $\phi_{22}$.

\section{Empirical analysis}

In this section, we use data from 19 OECD countries to examine whether the Fisher relation has empirical support internationally. Our main focus is on the ability of the alternative co-integration estimators to provide valid inference about the validity of the Fisher relationship. The empirical analysis is based on the same nine estimators included in the Monte Carlo experiment presented in the previous section.

\subsection{Data}

We use annual data for long-term interest rates and inflation rates available at the website of Professor Michael D. Bordo and the IFS database. The use of a long annual historical dataset stems from our need to increase the power of our testing methodology. Given that our focus is on the long-run equilibrium relation between interest rates and inflation rates, the findings in the literature indicate that the time span is far more important than the mere number of observations. In other words, co-integration is a long-run concept and therefore the literature suggests that it is preferable to conduct a co-integration analysis using low-frequency data over a long time period rather than high-frequency data over a short time period (see, among others, Hakkio and Rush, 1991; Otero and Smith, 2000; Zhou, 2001). 
Table 2: Empirical size for the Fisher hypothesis (VAR(1)-AR(1) model)

\begin{tabular}{|c|c|c|c|c|c|}
\hline & DGP1 & DGP7 & DGP8 & DGP9 & DGP10 \\
\hline$\sigma_{12}$ & 0.3 & 0.3 & 0.3 & 0.9 & 0.3 \\
\hline$\mu_{11}$ & 0.4 & 0.4 & 0.6 & 0.6 & 0.4 \\
\hline$\varphi_{11}$ & 0.0 & 0.6 & 0.4 & 0.4 & 0.6 \\
\hline$\varphi_{22}$ & 0.0 & 0.3 & 0.3 & 0.3 & 0.6 \\
\hline Panel A & \multicolumn{5}{|c|}{$\mathrm{T}=50$} \\
\hline OLS & 0.21 & 0.27 & 0.36 & 0.47 & 0.28 \\
\hline DOLS(hac) & 0.29 & 0.34 & 0.40 & 0.42 & 0.36 \\
\hline DOLS & 0.30 & 0.40 & 0.50 & 0.52 & 0.40 \\
\hline FMLS(nw) & 0.16 & 0.18 & 0.20 & 0.21 & 0.17 \\
\hline FMLS(a) & 0.14 & 0.18 & 0.19 & 0.19 & 0.17 \\
\hline $\operatorname{CCR}(\mathrm{nw})$ & 0.17 & 0.19 & 0.21 & 0.24 & 0.19 \\
\hline $\operatorname{CCR}(\mathrm{a})$ & 0.15 & 0.18 & 0.20 & 0.23 & 0.19 \\
\hline $\mathrm{JOH}$ & 0.19 & 0.25 & 0.29 & 0.28 & 0.25 \\
\hline AADL & 0.12 & 0.14 & 0.16 & 0.15 & 0.16 \\
\hline Panel B & \multicolumn{5}{|c|}{$\mathrm{T}=150$} \\
\hline OLS & 0.18 & 0.31 & 0.38 & 0.49 & 0.31 \\
\hline DOLS(hac) & 0.13 & 0.16 & 0.20 & 0.20 & 0.18 \\
\hline DOLS & 0.22 & 0.35 & 0.42 & 0.44 & 0.34 \\
\hline FMLS(nw) & 0.08 & 0.11 & 0.11 & 0.10 & 0.12 \\
\hline FMLS(a) & 0.07 & 0.11 & 0.11 & 0.09 & 0.11 \\
\hline $\operatorname{CCR}(\mathrm{nw})$ & 0.08 & 0.12 & 0.12 & 0.11 & 0.12 \\
\hline $\operatorname{CCR}(\mathrm{a})$ & 0.07 & 0.12 & 0.11 & 0.11 & 0.12 \\
\hline $\mathrm{JOH}$ & 0.09 & 0.11 & 0.13 & 0.11 & 0.12 \\
\hline AADL & 0.07 & 0.09 & 0.10 & 0.08 & 0.10 \\
\hline Panel C & \multicolumn{5}{|c|}{$\mathrm{T}=200$} \\
\hline OLS & 0.19 & 0.30 & 0.39 & 0.49 & 0.30 \\
\hline DOLS(hac) & 0.11 & 0.13 & 0.16 & 0.16 & 0.13 \\
\hline DOLS & 0.22 & 0.33 & 0.41 & 0.43 & 0.32 \\
\hline FMOLS(nw) & 0.07 & 0.08 & 0.08 & 0.08 & 0.09 \\
\hline FMOLS(a) & 0.06 & 0.09 & 0.08 & 0.08 & 0.09 \\
\hline $\mathrm{CCR}(\mathrm{nw})$ & 0.07 & 0.08 & 0.08 & 0.10 & 0.09 \\
\hline $\mathrm{CCR}(\mathrm{a})$ & 0.07 & 0.09 & 0.08 & 0.10 & 0.09 \\
\hline $\mathrm{JOH}$ & 0.07 & 0.07 & 0.08 & 0.09 & 0.09 \\
\hline AADL & 0.06 & 0.06 & 0.07 & 0.07 & 0.07 \\
\hline
\end{tabular}

Notes: The DGP is given by equations (2)-(3) and (5)-(8). 
We use the IFS database to extend the sample period to 2009 for all variables. However, the start date differs among countries due to data availability. Specifically, the sample starts in 1881 for Canada, Denmark, Ireland, the Netherlands, Sweden, the UK, and the USA; 1883 for Switzerland; 1947 for Australia, Belgium, and Norway; 1949 for France, Italy, New Zealand, and Portugal; 1955 for Germany; 1965 for Austria; 1966 for Japan; and 1970 for Luxembourg.

\subsection{Estimation results}

Some preliminary results confirm the widely held view that interest rates and inflation rates are I(1) processes and co-integrated. Specifically, we employ the trace statistic and the maximumeigenvalue statistic developed by Johansen $(1988,1991)$ and Johansen and Juselius (1990) to test for co-integration between interest rates and inflation rates. Both tests clearly suggest the existence of co-integration for almost all countries under scrutiny. Austria, Italy, Japan, and Luxembourg are the only exceptions. We should note however that the sample size for the aforementioned four countries is relatively small and this might influence the power of the tests to reveal co-integration (see, among others, Haug, 1996). In summary, our results suggest that the first condition for the Fisher hypothesis to hold is, in general, satisfied. In this mode, we focus on testing the second hypothesis, namely, that the slope coefficient is insignificantly different from 1.

Before proceeding to the estimation of the slope coefficient, $\theta$, we first establish its timeinvariancy property on the basis of tests for stability in co-integrating regressions (Hansen, 1992). Moreover, we employ three tests, namely, the $L_{c}, M e a n F$, and SupF tests, which test the null hypothesis that the co-integrating vector is constant. To save space, we provide a brief description of the tests along with our results in Appendix D. In the majority of cases, our findings (Table D1) point to the stability of the co-integrating relationship justifying our modelling approach. However, we can identify some exceptions. The tests uniformly reject the null hypothesis of a constant co-integrating parameter for Austria and Switzerland. Our results are mixed for Denmark, Italy, Portugal, and, to a lesser degree, France. France, Italy, and Switzerland are among the countries with a structural break in the co-integrating relation according to Haug et al. (2011).

Although our findings so far broadly support the existence of a time-invariant co-integrating relation between interest rates and inflation rates, we cannot rule out the possibility of the existence of a break in the Fisher equation for specific countries. Unfortunately, there is no straightforward way to differentiate between (i) a process with constant $\theta$ and time-varying dynamics in the error terms and (ii) a process with a time-varying $\theta$ and a constant coefficient process for the error terms. We believe that the former is more likely than the latter, since the literature indicates that the existence of a break in the co-integrating relation usually leads to co-integration test rejections (see Gregory et al., 1996; Davidson and Monticini, 2010; Haug et al., 2011).

In an attempt to further investigate this issue, we perform a simple Monte Carlo experiment, described in detail in Appendix E. In brief, we first consider a DGP with time-variation in the 
co-integrating parameter and examine how often the co-integration tests indicate the existence of co-integration. Then, we repeat the same procedure in the context of a DGP with a constant $\theta$ and time-varying dynamics in the error terms. In the former case, our findings confirm previous findings in the literature since the co-integration tests indicate the existence of co-integration in less than $20 \%$ of the generated samples. In the latter case, the power of the co-integration tests increases significantly exceeding $90 \%$ in some specifications. We, therefore, continue our empirical analysis assuming a constant $\theta$, keeping in mind, however, that this might not hold for specific countries, such as Austria and Italy where co-integration is not supported and the Hansen stability tests indicate a structural break in $\theta$.

We now proceed with the estimation of the slope coefficient. Table 3 presents the estimated value of $\theta$, along with the respective standard errors, for all the countries and estimators under consideration. First, we observe significant variation in the estimated slope coefficient both across estimators and across countries. The OLS estimator systematically produces the lowest estimates of $\theta$ with a median value of 0.233 , while the estimated $\theta$ s range from 0.01 (Ireland) to 0.64 (Austria). CCR and FMLS also generate, on average, low estimates of $\theta$, while JOH provides the highest ones with a median estimate of 1.308. A cross-country comparison reveals that Ireland and Switzerland generate, in general, the lowest estimates with a median of 0.01 and 0.065 respectively. On the other hand, Austria and Italy give the highest estimates with a median of 1 and 0.724 , respectively.

Next, we test the null hypothesis that $\theta$ equals unity for all countries under scrutiny based on the nine different estimators considered in the analysis. The t-statistics for the null hypothesis of $\theta=1$ are reported in Table 4. Entries in bold indicate rejection of the null hypothesis based on $5 \%$ asymptotic critical values. Our findings suggest that in most cases, the Fisher hypothesis is rejected. Specifically, eight out of the nine estimators lead to the rejection of the null hypothesis for France, Ireland, the Netherlands, Portugal, and Switzerland. In most countries, at least four estimators suggest that $\theta$ is not equal to unity. The countries with the strongest evidence in favour of the Fisher hypothesis are Austria and Luxembourg. For these two countries, all estimators, other than OLS, do not reject the null hypothesis. As far as the behaviour of the estimators is concerned, we observe many differences. The results based on the OLS estimator suggest rejection of the Fisher hypothesis in all 19 countries under scrutiny. Similarly, CCR produces t-statistics that reject the Fisher hypothesis for 15 or 16 countries depending on the version of the estimator. On the other hand, the results of AADL indicate that the null hypothesis is rejected in only four countries. It is interesting to note that, according to our previous simulations, AADL is the most robust estimator to DGPs with time-varying dynamics. The remaining estimators reject the null hypothesis for 8 to 12 countries.

So far, the results produced by most estimators provide evidence against the validity of the Fisher hypothesis. These findings are based on asymptotic critical values that might be inappropriate for small sample sizes such as ours consisting of 40 to 128 observations. Moreover, it is possible that the DGP of both interest rates and inflation rates has time-varying coefficients. In such cases, the results of the Monte Carlo experiment presented in Section 2 reveal that the 
Table 3: Estimation results for the co-integrating parameter in the Fisher equation

\begin{tabular}{|c|c|c|c|c|c|c|c|c|c|}
\hline & $\overline{\text { OLS }}$ & $\begin{array}{c}\text { DOLS } \\
(\text { hac })\end{array}$ & DOLS & $\begin{array}{c}\text { FMLS } \\
(n w)\end{array}$ & $\begin{array}{c}\text { FMLS } \\
\text { (a) }\end{array}$ & $\begin{array}{l}\mathrm{CCR} \\
(\mathrm{nw})\end{array}$ & $\begin{array}{c}\mathrm{CCR} \\
\text { (a) }\end{array}$ & $\overline{\mathrm{JOH}}$ & 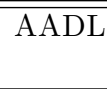 \\
\hline Australia & $\begin{array}{l}0.259^{*} \\
(0.091)\end{array}$ & $\begin{array}{l}1.572^{*} \\
(0.288)\end{array}$ & $\begin{array}{l}1.572^{*} \\
(0.185)\end{array}$ & $\begin{array}{c}0.509 \\
(0.312)\end{array}$ & $\begin{array}{c}0.501 \\
(0.309)\end{array}$ & $\begin{array}{c}0.466 \\
(0.284)\end{array}$ & $\begin{array}{c}0.456 \\
(0.278)\end{array}$ & $\begin{array}{l}2.078^{*} \\
(0.434)\end{array}$ & $\begin{array}{l}1.362^{*} \\
(0.355)\end{array}$ \\
\hline Austria & $\begin{array}{l}.640^{*} \\
.088)\end{array}$ & $\begin{array}{l}1.101^{*} \\
(0.159)\end{array}$ & $\begin{array}{l}1.101^{*} \\
(0.093)\end{array}$ & $\begin{array}{l}1.000^{*} \\
(0.338)\end{array}$ & $\begin{array}{l}0.945^{*} \\
(0.326)\end{array}$ & $\begin{array}{l}0.943^{*} \\
(0.310)\end{array}$ & $\begin{array}{l}0.928^{*} \\
(0.317)\end{array}$ & $\begin{array}{l}1.214^{*} \\
(0.242)\end{array}$ & $\begin{array}{l}1.186^{*} \\
(0.495)\end{array}$ \\
\hline Belgium & $\begin{array}{l}0.152^{*} \\
(0.038)\end{array}$ & $\begin{array}{l}0.998^{*} \\
(0.129)\end{array}$ & $\begin{array}{c}0.998^{*} \\
(0.066)\end{array}$ & $\begin{array}{c}0.239 \\
(0.198)\end{array}$ & $\begin{array}{c}0.370 \\
(0.213)\end{array}$ & $\begin{array}{c}0.256 \\
(0.216)\end{array}$ & $\begin{array}{c}0.356 \\
(0.205)\end{array}$ & $\begin{array}{l}1.308^{*} \\
(0.174)\end{array}$ & $\begin{array}{c}0.416 \\
(0.254)\end{array}$ \\
\hline Canas & $\begin{array}{l}0.201^{*} \\
(0.046)\end{array}$ & $\begin{array}{l}1.173^{*} \\
(0.191)\end{array}$ & $\begin{array}{l}1.173^{*} \\
(0.094)\end{array}$ & $\begin{array}{c}0.388 \\
(0.260)\end{array}$ & $\begin{array}{l}0.675^{*} \\
(0.225)\end{array}$ & $\begin{array}{c}0.414 \\
(0.278)\end{array}$ & $\begin{array}{l}0.361^{*} \\
(0.131)\end{array}$ & $\begin{array}{l}1.547^{*} \\
(0.188)\end{array}$ & $\begin{array}{l}0.876^{*} \\
(0.359)\end{array}$ \\
\hline Den & $\begin{array}{c}0.233^{*} \\
(0.047)\end{array}$ & $\begin{array}{c}1.303^{*} \\
(0.288)\end{array}$ & $\begin{array}{l}1.303^{*} \\
(0.105)\end{array}$ & $\begin{array}{c}0.571^{*} \\
(0.252)\end{array}$ & $\begin{array}{l}0.561^{*} \\
(0.260)\end{array}$ & $\begin{array}{l}0.466^{*} \\
(0.209)\end{array}$ & $\begin{array}{l}0.426^{*} \\
(0.200)\end{array}$ & $\begin{array}{l}1.547^{*} \\
(0.215)\end{array}$ & $\begin{array}{l}0.740^{*} \\
(0.337)\end{array}$ \\
\hline France & $\begin{array}{l}0.127^{*} \\
(0.030)\end{array}$ & $\begin{array}{l}0.792^{*} \\
(0.068)\end{array}$ & $\begin{array}{l}0.792^{*} \\
(0.065)\end{array}$ & $\begin{array}{c}0.300 \\
(0.158)\end{array}$ & $\begin{array}{c}0.278 \\
(0.172)\end{array}$ & $\begin{array}{c}0.213 \\
(0.111)\end{array}$ & $\begin{array}{c}0.225 \\
(0.139)\end{array}$ & $\begin{array}{l}1.113^{*} \\
(0.177)\end{array}$ & $\begin{array}{c}0.388 \\
(0.203)\end{array}$ \\
\hline Gel & & $\begin{array}{l}1.273^{*} \\
(0.142)\end{array}$ & $\begin{array}{l}1.273^{*} \\
(0.108)\end{array}$ & $\begin{array}{l}0.701^{*} \\
(0.239)\end{array}$ & $\begin{array}{l}0.797^{*} \\
(0.251)\end{array}$ & $\begin{array}{l}0.551^{*} \\
(0.203)\end{array}$ & $\begin{array}{l}0.521^{*} \\
(0.188)\end{array}$ & $\begin{array}{l}2.734^{*} \\
(0.415)\end{array}$ & $\begin{array}{c}0.277 \\
(0.384)\end{array}$ \\
\hline Italy & $\begin{array}{l}0.556^{*} \\
(0.066)\end{array}$ & & $\begin{array}{c}0.907^{*} \\
(0.052)\end{array}$ & $\begin{array}{l}0.724^{*} \\
(0.138)\end{array}$ & & & & $\begin{array}{l}0.966^{*} \\
(0.159)\end{array}$ & $\begin{array}{l}0.960^{*} \\
(0.228)\end{array}$ \\
\hline Irela & $\begin{array}{c}0.010 \\
(0.009)\end{array}$ & $\begin{array}{c}0.013 \\
(0.015)\end{array}$ & $\begin{array}{c}0.013 \\
(0.011)\end{array}$ & $\begin{array}{c}-0.022 \\
(0.041)\end{array}$ & $\begin{array}{c}0.004 \\
(0.043)\end{array}$ & & $\begin{array}{c}0.003 \\
(0.046)\end{array}$ & $\begin{array}{l}1.047^{*} \\
(0.231)\end{array}$ & $\begin{array}{c}0.084 \\
(0.081)\end{array}$ \\
\hline Japan & $0.459^{*}$ & $\begin{array}{l}0.816^{*} \\
(0.075)\end{array}$ & & $\begin{array}{c}0.663^{*} \\
(0.195)\end{array}$ & $\begin{array}{l}0.604^{*} \\
(0.222)\end{array}$ & $\begin{array}{l}0.576^{*} \\
(0.148)\end{array}$ & $\begin{array}{l}0.586^{*} \\
(0.208)\end{array}$ & $\begin{array}{l}0.917^{*} \\
(0.164)\end{array}$ & $\begin{array}{l}0.660^{*} \\
(0.236)\end{array}$ \\
\hline $\mathrm{Lu}$ & & $\begin{array}{l}0.873^{*} \\
(0.198)\end{array}$ & & $\begin{array}{l}0.701^{*} \\
(0.326)\end{array}$ & $\begin{array}{c}0.643 \\
(0.335)\end{array}$ & $\begin{array}{l}0.572^{*} \\
(0.263)\end{array}$ & $\begin{array}{c}0.568 \\
(0.292)\end{array}$ & $\begin{array}{l}2.045^{*} \\
(0.575)\end{array}$ & $\begin{array}{c}1.219 \\
(0.741)\end{array}$ \\
\hline $\mathrm{N}$ & & & & & $\begin{array}{c}0.207 \\
(0.176)\end{array}$ & & $\begin{array}{c}0.168 \\
(0.143)\end{array}$ & & $\begin{array}{c}0.550 \\
(0.343)\end{array}$ \\
\hline $\mathrm{Ne}$ & & $\begin{array}{l}0.461^{*} \\
(0.097)\end{array}$ & $\begin{array}{l}0.461^{*} \\
(0.075)\end{array}$ & $\begin{array}{l}0.526^{*} \\
(0.158)\end{array}$ & $\begin{array}{l}0.507^{*} \\
(0.155)\end{array}$ & $\begin{array}{l}0.491^{*} \\
(0.125)\end{array}$ & $\begin{array}{l}0.479^{*} \\
(0.122)\end{array}$ & $\begin{array}{l}1.099^{*} \\
(0.180)\end{array}$ & $\begin{array}{l}0.880^{*} \\
(0.223)\end{array}$ \\
\hline $\mathrm{N}$ & $\begin{array}{l}0.398^{*} \\
(0.111)\end{array}$ & $\begin{array}{l}0.607^{*} \\
(0.142)\end{array}$ & $\begin{array}{c}0.607^{*} \\
(0.139)\end{array}$ & $\begin{array}{c}1.120 \\
(0.633)\end{array}$ & $\begin{array}{l}1.269^{*} \\
(0.447)\end{array}$ & $\begin{array}{c}0.661 \\
(0.382)\end{array}$ & $\begin{array}{l}0.559^{*} \\
(0.192)\end{array}$ & $\begin{array}{l}2.226^{*} \\
(0.410)\end{array}$ & $\begin{array}{l}1.701^{*} \\
(0.680)\end{array}$ \\
\hline Por & $\begin{array}{l}0.516^{*} \\
(0.053)\end{array}$ & $\begin{array}{l}0.690^{*} \\
(0.017)\end{array}$ & $\begin{array}{l}0.690^{*} \\
(0.020)\end{array}$ & $\begin{array}{l}0.653^{*} \\
(0.062)\end{array}$ & $\begin{array}{l}0.673^{*} \\
(0.068)\end{array}$ & $\begin{array}{l}0.581^{*} \\
(0.043)\end{array}$ & $\begin{array}{l}0.589^{*} \\
(0.047)\end{array}$ & $\begin{array}{l}0.788^{*} \\
(0.069)\end{array}$ & $\begin{array}{l}0.781^{*} \\
(0.115)\end{array}$ \\
\hline $\mathrm{S}$ & $\begin{array}{l}0.139 \\
(0.03\end{array}$ & $\begin{array}{l}0.879^{*} \\
(0.209)\end{array}$ & $\begin{array}{c}0.879^{*} \\
(0.081)\end{array}$ & $\begin{array}{l}0.579^{*} \\
(0.206)\end{array}$ & $\begin{array}{l}0.875^{*} \\
(0.236)\end{array}$ & $\begin{array}{l}0.588^{*} \\
(0.208)\end{array}$ & $\begin{array}{l}0.268^{*} \\
(0.098)\end{array}$ & $\begin{array}{l}1.503^{*} \\
(0.283)\end{array}$ & $\begin{array}{c}0.573 \\
(0.371)\end{array}$ \\
\hline Switz & $\begin{array}{c}0.042^{*} \\
(0.017)\end{array}$ & $\begin{array}{l}0.099^{*} \\
(0.045)\end{array}$ & $\begin{array}{l}0.099^{*} \\
(0.024)\end{array}$ & $\begin{array}{c}0.049 \\
(0.078)\end{array}$ & $\begin{array}{c}0.065 \\
(0.075)\end{array}$ & $\begin{array}{c}0.049 \\
(0.080)\end{array}$ & $\begin{array}{c}0.062 \\
(0.071)\end{array}$ & $\begin{array}{l}0.946^{*} \\
(0.146)\end{array}$ & $\begin{array}{c}0.172 \\
(0.102)\end{array}$ \\
\hline UK & $\begin{array}{c}0.295^{*} \\
(0.040)\end{array}$ & $\begin{array}{l}1.018^{*} \\
(0.145)\end{array}$ & $\begin{array}{l}1.018^{*} \\
(0.069)\end{array}$ & $\begin{array}{l}0.603^{*} \\
(0.183)\end{array}$ & $\begin{array}{l}0.690^{*} \\
(0.174)\end{array}$ & $\begin{array}{l}0.512^{*} \\
(0.154)\end{array}$ & $\begin{array}{l}0.447^{*} \\
(0.108)\end{array}$ & $\begin{array}{l}1.173^{*} \\
(0.183)\end{array}$ & $\begin{array}{l}0.605^{*} \\
(0.205)\end{array}$ \\
\hline USA & $\begin{array}{c}0.169^{*} \\
(0.044)\end{array}$ & $\begin{array}{l}1.125^{*} \\
(0.270)\end{array}$ & $\begin{array}{l}1.125^{*} \\
(0.107)\end{array}$ & $\begin{array}{c}0.375 \\
(0.223)\end{array}$ & $\begin{array}{c}0.381 \\
(0.235)\end{array}$ & $\begin{array}{c}0.344 \\
(0.205)\end{array}$ & $\begin{array}{c}0.328 \\
(0.204)\end{array}$ & $\begin{array}{l}1.637^{*} \\
(0.243)\end{array}$ & $\begin{array}{l}0.774^{*} \\
(0.327)\end{array}$ \\
\hline
\end{tabular}

Notes: Standard errors are reported in parentheses.

An asterisk indicates a statistically significant estimate $(\alpha=5 \%)$. 
Table 4: t-statistic for the null hypothesis of a unit coefficient in the Fisher equation

\begin{tabular}{|c|c|c|c|c|c|c|c|c|c|}
\hline & $\overline{\text { OLS }}$ & $\begin{array}{c}\text { DOLS } \\
\text { (hac) }\end{array}$ & $\overline{\mathrm{DOLS}}$ & $\begin{array}{c}\text { FMLS } \\
(\mathrm{nw})\end{array}$ & $\begin{array}{l}\text { FMLS } \\
\text { (a) }\end{array}$ & $\begin{array}{l}\text { CCR } \\
(\mathrm{nw})\end{array}$ & $\begin{array}{l}\text { CCR } \\
\text { (a) }\end{array}$ & $\overline{\mathrm{JOH}}$ & $\overline{\overline{\mathrm{AADL}}}$ \\
\hline Australia & -8.142 & 1.989 & 3.087 & -1.574 & -1.616 & -1.883 & -1.955 & 2.485 & 1.018 \\
\hline Austria & -4.099 & 0.633 & 1.086 & 0.000 & -0.167 & -0.183 & -0.226 & 0.883 & 0.375 \\
\hline Belgium & $-22.60 *$ & -0.017 & -0.033 & -3.838 & -2.961 & -3.451 & -3.141 & 1.768 & -2.303 \\
\hline Canada & $-17.32 *$ & 0.904 & 1.848 & -2.350 & -1.444 & -2.106 & -4.881 & 2.905 & -0.346 \\
\hline Denmark & -16.218 & 1.052 & 2.882 & -1.700 & -1.691 & -2.551 & -2.875 & 2.546 & -0.772 \\
\hline France & $-29.31 *$ & -3.034 & -3.184 & -4.441 & -4.194 & $-7.064^{*}$ & -5.587 & 0.639 & -3.015 \\
\hline Germany & $-13.86^{*}$ & 1.916 & 2.532 & -1.253 & -0.807 & -2.215 & -2.555 & 4.183 & -1.883 \\
\hline Italy & -6.690 & -1.696 & -1.797 & -2.004 & -2.094 & -2.909 & -2.618 & -0.212 & -0.174 \\
\hline Ireland & $-108.02 *$ & $-66.25^{*}$ & $-90.30 *$ & $-24.85^{*}$ & $-23.28^{*}$ & $-21.48^{*}$ & $-21.62 *$ & 0.204 & $-11.35^{*}$ \\
\hline Japan & $-8.426 *$ & -2.441 & -3.160 & -1.728 & -1.788 & -2.861 & -1.993 & -0.508 & -1.443 \\
\hline Luxembourg & -6.632 & -0.644 & -0.815 & -0.917 & -1.068 & -1.627 & -1.483 & 1.817 & 0.295 \\
\hline Netherlands & $-27.23^{*}$ & -3.228 & -9.462 & -5.510 & -4.514 & -5.735 & -5.839 & 2.900 & -1.313 \\
\hline New Zealand & -7.449 & -5.546 & -7.176 & -3.003 & -3.173 & -4.084 & -4.279 & 0.552 & -0.540 \\
\hline Norway & -5.443 & -2.768 & -2.822 & 0.189 & 0.602 & -0.888 & -2.297 & 2.992 & 1.029 \\
\hline Portugal & -9.181 & $-18.53^{*}$ & $-15.37 *$ & -5.574 & -4.802 & $-9.832 *$ & $-8.810^{*}$ & -3.100 & -1.894 \\
\hline Sweden & $-22.77^{*}$ & -0.580 & -1.507 & -2.039 & -0.529 & -1.976 & $-7.444^{*}$ & 1.775 & -1.152 \\
\hline Switzerland & $-56.94^{*}$ & $-20.20^{*}$ & $-38.05^{*}$ & $-12.22^{*}$ & $-12.40 *$ & $-11.88^{*}$ & $-13.18^{*}$ & -0.370 & $-8.09 *$ \\
\hline UK & $-17.47^{*}$ & 0.124 & 0.259 & -2.170 & -1.779 & -3.169 & -5.112 & 0.943 & -1.927 \\
\hline USA & $-18.70 *$ & 0.464 & 1.167 & -2.809 & -2.638 & -3.202 & -3.296 & 2.623 & -0.692 \\
\hline
\end{tabular}

Notes: Bold indicates rejection of the null hypothesis of a unit coefficient based on asymptotic critical values. An asterisk indicates rejection of the null hypothesis of a unit coefficient based on simulated critical values.

estimators considered in this analysis suffer from significant size distortions. Therefore, the utilisation of asymptotic critical values seems problematic and can lead to false conclusions. We overcome these issues by repeating the analysis based on simulated critical values that take into account both the small sample size and the time-varying dynamics.

In order to generate the simulated critical values, we first need to choose the proper DGP to describe the relationship between the interest rate and the inflation of each country. We consider three alternative models; the $\operatorname{VAR}(1)-\operatorname{AR}(1)$ and $\operatorname{VAR}(1)-\mathrm{RC}$ models described in Section 2, and a simple $\operatorname{VAR}(1)$ model with constant coefficients. The constant coefficient $\operatorname{VAR}(1)$ model is a simplified version of $\operatorname{VAR}(1)-\mathrm{RC}$ where $\rho_{11, t}$ and $\rho_{22, t}$ are not included in the model of $\mathbf{u}_{t}$. Specifically, $u_{t}=M u_{t-1}+e_{t}$ where $M$ is a diagonal $2 \times 2$ matrix and $e_{t} \sim \operatorname{NIID}\left(\mathbf{0}, \Sigma_{12}\right)$. For each country under examination, we select among the three models by means of the likelihood ratio (LR) statistic. Once again, we use simulated critical values instead of asymptotic ones to ensure correct inference. The values of the LR statistic, together with the $5 \%$ simulated critical values and the selected model are reported in Table 5 . The general VAR(1)-AR(1) model is selected for nine countries, while the $\operatorname{VAR}(1)$-RC model is also selected for nine countries. On the other hand, the constant coefficient VAR(1) model is supported only for Austria.

Given the selected model for each country, we now calculate the simulated critical values (not reported) for each estimator. In this way, we can conduct proper statistical inference for the null hypothesis that $\theta$ equals unity. An asterisk on the estimates reported in Table 4 indicates rejection of the null hypothesis based on simulated critical values. In a nutshell, this last set of results paints a totally different picture. We now provide strong evidence supporting the validity of the Fisher hypothesis. To be more specific, all the estimators lead to the same conclusion that $\theta=1$ in almost all cases. OLS is the only exception since it still suggests rejection of the 
Table 5: Model selection (LR-statistic)

\begin{tabular}{|c|c|c|c|c|c|c|c|}
\hline & & \multicolumn{3}{|c|}{ LR-statistic } & \multicolumn{3}{|c|}{ Simulated critical values $(\alpha=5 \%)$} \\
\hline & Selected & VAR-AR & VAR-AR & VAR-RC & VAR-AR & VAR-AR & VAR-RC \\
\hline & & vs. & vs. & vs. & vs. & vs. & vs. \\
\hline & Model & VAR-RC & VAR & VAR & VAR-RC & VAR & VAR \\
\hline Australia & VAR-RC & 2.245 & 21.448 & 19.203 & 5.642 & 9.778 & 7.630 \\
\hline Austria & VAR & 1.116 & 7.522 & 6.406 & 3.904 & 9.025 & 7.454 \\
\hline Belgium & VAR-AR & 7.114 & 40.546 & 33.433 & 6.057 & 9.041 & 7.496 \\
\hline Canada & VAR-AR & 17.665 & 72.318 & 54.653 & 7.172 & 10.34 & 8.763 \\
\hline Denmark & VAR-AR & 11.466 & 75.761 & 64.295 & 6.431 & 10.44 & 8.173 \\
\hline France & VAR-RC & 1.105 & 45.454 & 44.349 & 6.317 & 9.626 & 8.012 \\
\hline Germany & VAR-RC & 1.412 & 11.670 & 10.258 & 4.704 & 8.632 & 7.097 \\
\hline Italy & VAR-RC & 1.458 & 13.160 & 11.701 & 7.681 & 9.028 & 6.915 \\
\hline Ireland & VAR-AR & 16.363 & 340.040 & 323.677 & 5.930 & 9.277 & 7.327 \\
\hline Japan & VAR-RC & 2.329 & 11.633 & 9.603 & 7.836 & 11.156 & 9.467 \\
\hline Luxembourg & VAR-AR & 16.658 & 19.699 & 3.041 & 4.589 & 9.220 & 7.595 \\
\hline Netherlands & VAR-AR & 6.218 & 40.816 & 34.599 & 5.172 & 9.406 & 7.330 \\
\hline New Zealand & VAR-RC & 2.677 & 12.914 & 10.237 & 4.589 & 8.876 & 7.142 \\
\hline Norway & VAR-RC & 3.050 & 12.614 & 9.564 & 5.745 & 9.781 & 8.057 \\
\hline Portugal & VAR-AR & 25.837 & 39.485 & 13.648 & 5.760 & 9.062 & 6.978 \\
\hline Sweden & VAR-AR & 8.574 & 79.919 & 71.345 & 6.142 & 9.492 & 7.772 \\
\hline Switzerland & VAR-RC & 0.834 & 53.665 & 52.831 & 6.108 & 8.125 & 6.508 \\
\hline UK & VAR-RC & 0.772 & 107.810 & 107.039 & 10.14 & 8.752 & 7.036 \\
\hline USA & VAR-AR & 7.448 & 62.840 & 55.392 & 6.102 & 9.858 & 8.232 \\
\hline
\end{tabular}


Fisher hypothesis for 11 countries. If we concentrate on the other eight estimators, they all support the Fisher hypothesis for 14 countries (Australia, Austria, Belgium, Canada, Denmark, Germany, Italy, Japan, Luxembourg, the Netherlands, New Zealand, Norway, the UK, and the USA), while seven of them support the Fisher hypothesis for France and Sweden. The results are mixed for Portugal where four estimators lead to the rejection of the Fisher hypothesis. However, we should note that the estimators with the best Monte Carlo performance, namely, AADL and both versions of FMLS, support the validity of the Fisher hypothesis in Portugal. On the other hand, Ireland and Switzerland are the only cases where almost all the estimators reject the Fisher hypothesis.

\section{Conclusions}

This study examines the Fisher hypothesis for 19 OECD countries. We consider the case of timevarying dynamics in the error generating process of both interest rates and inflation rates. In such cases, the behaviour of the co-integration estimators that are usually utilised to investigate the validity of the Fisher hypothesis can be affected leading to incorrect conclusions.

We first use Monte Carlo simulations to examine the properties of nine alternative estimators under DGPs with time-varying coefficients. Our results suggest that the estimators suffer from significant size distortions, especially for small sample sizes. The AADL estimator appears to be the most robust estimator to time-varying dynamics, closely followed by the FMLS estimator.

Next, we employ 19 OECD countries to examine whether the Fisher relation has empirical support internationally. The findings crucially depend on the critical values used to test the Fisher hypothesis. When we use asymptotic critical values, which, according to our Monte Carlo experiment, are inappropriate for correct inference in cases of small samples and/or DGPs with time-varying dynamics, empirical evidence is usually against the validity of the Fisher hypothesis. AADL is the only exception since this estimator rejects the Fisher hypothesis for only four countries. On the other hand, when we use simulated critical values that take into account both the available sample size and the time-varying dynamics of the data generating process, the picture changes dramatically. All the estimators under scrutiny, with the exception of OLS, strongly support the validity of the Fisher hypothesis. The only exceptions are Ireland and Switzerland where almost all estimators reject the Fisher hypothesis, while the results are mixed in the case of Portugal. 


\section{References}

[1]Andrews D.W.K. (1991), Heteroskedasticity and autocorrelation consistent covariance matrix estimation. Econometrica, 59, 817-858.

[2]Andrews D.W.K. and J.C. Monahan (1992), An improved heteroskedasticity and autocorrelation consistent covariance matrix estimator, Econometrica, 60, 953-966.

[3]Atkins F. J. and P. J. Coe. (2002), An ARDL bounds test approach to testing the long-run Fisher effect in the United States and Canada, Journal of Macroeconomics, 24 (2), 255-266.

[4]Banerjee A., Dolado, J.J., Galbraith, J.W. and D.F. Hendry (1993), Cointegration, Error Correction and the Econometric Analysis of Non-Stationary Data, Oxford, Oxford University Press.

[5]Bewley R.A (1979), The direct estimation of the equilibrium response in a linear model, Economics Letters, 3, 357-61.

[6]Bierens H.J. (2000), Non-parametric nonlinear co-trending analysis, with an application to inflation and interest in the US. Journal of Business and Economic Statistics, 18, 323-337.

[7]Bierens, H.J. and L.F. Martins (2010), Time-varying cointegration. Econometric Theory 26, 1453-1490.

[8]Caporale G.M. and N. Pittis (2004), Estimator choice and Fisher's paradox: A Monte Carlo study, Econometric Reviews , 23(1), 25-52.

[9]Christopoulos D and M. Leon-Ledesma (2007), A long-run nonlinear approach to the Fisher effect, Journal of Money, Credit and Banking, 39, 543-559.

[10]Christou C. and N. Pittis (2002), Kernel and bandwidth selection, prewhitening, and the performance of the Fully Modified Least Squares estimation method. Econometric Theory, 18, 948-961.

[11]Coakley J, A.M. Fuertes and R. Smith (2006), Unobserved heterogeneity in panel time series models, Computational Statistics \& Data Analysis, 50, 2361-2380.

[12]Cooray A. (2003), The Fisher effect: A survey. The Singapore Economic Review, 48(2), 135-150.

[13]Crowder W. and D. Hoffman (1996), The long-run relation between nominal interest rates and inflation: The Fisher equation revisited. Journal of Money, Credit and Banking, 28, 102-118.

[14]Darby M.R. (1975), The financial and tax effects of monetary policy on interest rates, Economic Inquiry, 13, 266-269.

[15]Davidson J. and A. Monticini (2010), Tests for cointegration with structural breaks based on subsamples, Computational Statistics 83 Data Analysis, 54, 2498-2511.

[16]Engle R.F. and C.W.J Granger (1987), Cointegration and error correction representation, estimation and testing, Econometrica, 55, 251-276.

[17]Evans M. and K.Lewis (1995), Do expected shifts in inflation affect estimates of the long-run fisher relation? Journal of Finance, 50, 225-253. 
[18]Fahmy Y A. F. and M. Kandil (2003), The Fisher effect: new evidence and implications, International Review of Economics \& Finance, 12, 4, 451-465.

[19]Fisher I. (1930), The theory of interest, Macmillan.

[20]Gregory, A.W., J.M. Nason and D.G. Watt (1996), Testing for structural breaks in cointegrated relationships, Journal of Econometrics, 71, 321-341.

[21]Hakkio C.S. and M. Rush, (1991), Cointegration: how short is the long run? Journal of International Money and Finance, 10, 571-581.

[22]Hansen B. (1992), Tests for parameter instability in regressions with I(1) processes, Journal of Business and Economic Statistics, 10, 321-335.

[23]Haug A.A. (1996), Tests for Cointegration: A Monte Carlo Comparison, Journal of Econometrics, 71, 81-115.

[24]Haug A.A., A. Beyer and W. Dewald (2011), Structural Breaks and the Fisher Effect, The B.E. Journal of Macroeconomics 11(1), article 9, 1-29.

[25]Johansen S. (1988), Statistical analysis of cointegrating vectors, Journal of Economic Dynamics and Control, 12, 231-254.

[26]Johansen S. (1991), Estimation and hypothesis testing of cointegration vectors in Gaussian vector autoregressive models, Econometrica, 59, 1551-1580.

[27]Johansen, S. and K. Juselius (1990), Maximum likelihood estimation and inference on cointegration - With application to the demand for money, Oxford Bulletin of Economics and Statistics 52, 169-210.

[28]Judge G., R.C. Hill, W. Griffiths, H. Lutkepohl and T.C. Lee (1988), Introduction to the Theory and Practice of Econometrics, John Wiley \& Sons.

[29]Kapetanios G., Shin, Y, and A, Snell (2003), Testing for a unit root in the nonlinear STAR framework. Journal of Econometrics, 112, 359-379.

[30]Koop G., R. Leon-Gonzalez and R. Strachan (2011), Bayesian Inference in the Time Varying Cointegration Model, Journal of Econometrics, 165(2), 210-220.

[31]Koustas Z, and J-F Lamarche (2010), Evidence of non-linear mean reversion in the real interest rate. Applied Economics, 42(2), 237-248.

[32]Koustas Z. and A. Serletis (1999), On the Fisher effect. Journal of Monetary Economics, 44(1):105-30.

[33]Lanne M. (2006), Nonlinear dynamics of interest and inflation, Journal of Applied Econometrics, 21,1157-1168.

[34]Lutkepohl H. (1993), Introduction to Multiple Time Series Analysis, Springer-Verlag, New York.

[35]Mishkin F.S.(1992), Is the Fisher effect for real? A reexamination of the relationship between inflation and interest rates. Journal of Monetary Economics, 30, 195-215.

[36]Newey W.K. and K.D. West (1987), A simple positive, semi-definite, heteroskedasticity and autocorrelation consistent covariance matrix, Econometrica, 55, 703-708. 
[37]Newey W.K. and K.D. West (1994), Automatic lag selection in covariance matrix estimation, Review of Economic Studies, 61, 4, 631-653.

[38]Nichols Des F. and B.G. Quinn (1982), Random Coefficient Autoregressive Models: An Introduction, Lecture Notes in Statistics, Springer-Verlag.

[39] Otero J. and J. Smith (2000), Testing for cointegration: power versus frequency of observation - further Monte Carlo results, Economics Letters, 67, 5-9.

[40]Panopoulou E. and N. Pittis (2004), A comparison of autoregressive distributed lag and dynamic OLS cointegration estimators in the case of a serially correlated cointegration error, The Econometrics Journal, 7(2), 585-617.

[41]Park J.Y. (1992). Canonical cointegrating regressions, Econometrica, 60, 119-143.

[42]Pesaran H.M. and Y. Shin (1999), An Autoregressive Distributed Lag Modelling Approach to Cointegration Analysis, Econometrics and Economic Theory in the 20th Century: The Ragnar Frisch Centennial Symposium, chapter 11. Cambridge University Press, Cambridge.

[43]Phillips P.C.B. (1988), Reflections on econometric methodology, Economic Record, 64, 344359.

[44]Phillips P.C.B. and S.N. Durlauf, (1986), Multiple time series regression with integrated processes, Review of Economic Studies 53, 473-496.

[45]Phillips P.C.B. and E.J. Hansen (1990), Statistical inference in instrumental regressions with I(1) processes, Review of Economic Studies, 57, 99-125.

[46]Phillips P.C.B. and M. Loretan (1991), Estimating long-run economic equilibria, Review of Economic Studies, 58, 407-436.

[47]Rose A.(1988) Is the Real Interest Rate Stable? Journal of Finance, 43(5):1095-1112.

[48]Saikkonen P. (1991), Asymptotically efficient estimation of the cointegrating regressions, Econometric Theory, 7,1, 1-27.

[49]Stock J.H. and M.W. Watson (1993), A simple estimator of cointegrating vectors in higherorder integrated systems, Econometrica, 61, 783-820.

[50]Trecroci C. and M. Vassalli (2010), Monetary policy regime shifts: New evidence from time-varying interest rate rules, Economic Inquiry, 48(4), 933-950.

[51]Wickens M.R. and T.S. Breusch (1988), Dynamic specification, the long run and the estimation of transformed regression models, Economic Journal, 98, (Conference 1988), 189-205.

[52]Weiss A. (1985), The stability of the AR(1) process with an AR(1) coefficient, Journal of Time Series Analysis, 6(3), 181-186.

[53]Westerlund J. (2008), Panel cointegration tests of the Fisher effect, Journal of Applied Econometrics, 23, 193-233.

[54]Zhou S. (2001), The power of cointegration tests versus data frequency and time spans, Southern Economic Journal, 67 (4), 906-921. 
Appendix A: Stationarity conditions for $\mathbf{u}_{t}=\left[u_{1 t}, u_{2 t}\right]^{\top}$

\section{A1: Stationarity conditions for the $\operatorname{VAR}(1)-\operatorname{AR}(1)$ case.}

Consider the process $\mathbf{u}_{t}=\left[u_{1 t}, u_{2 t}\right]^{\top}$ given by equations (4)-(8). According to Weiss (1985), the stability condition for $u_{1 t}$ and $u_{2 t}$ is (dropping the subscripts) $R+S^{2}(\infty) \prec 1$, with

$$
\begin{aligned}
R+S^{2}(\infty)= & \mu^{2}+\frac{q}{1-\phi^{2}}\left(1+4 \mu^{2}+8 \mu^{2} \lim _{n \rightarrow \infty} \sum_{j=1}^{n-1} \frac{n-j}{n} \phi^{j}\right)+ \\
& \frac{2 q^{2}}{\left(1-\phi^{2}\right)^{2}}\left(1+\lim _{n \rightarrow \infty} \sum_{j=1}^{n-1} \frac{n-j}{n} \phi^{2 j}\right),
\end{aligned}
$$

where $q$ equals $\sigma_{33}$ and $\sigma_{44}$ for the case of $u_{1 t}$ and $u_{2 t}$ respectively.

In general, stability does not imply stationarity. However, implicit in the derivation of the stability condition by Weiss is the existence of a finite mean and the condition itself is built on the requirement of a finite variance, which associated with an identical distribution for the errors $e_{t}$ provide us with a sufficient second-order stationarity condition, albeit a strong one.

\section{A2: Stationarity conditions for the VAR(1)-RC case.}

Nicholls and Quinn (1982) derived the stationarity conditions for the multivariate autoregressive model of order n. In our case, their conditions (necessary and sufficient) are as follows:

1.The eigenvalues of the matrix $M$ are less than unity. Given that $M$ is diagonal, its eigenvalues are less than unity in modulus $\Longleftrightarrow\left|\mu_{11}\right|<1$ and $\left|\mu_{22}\right|<1$, and

2.The matrix $H=\left(\begin{array}{cc}\sigma_{11} \frac{1-\mu_{11}^{2}}{1-\mu_{11}^{2}-\sigma_{33}} & \sigma_{12} \\ \sigma_{12} & \sigma_{22} \frac{1-\mu_{22}^{2}}{1-\mu_{22}^{2}-\sigma_{44}}\end{array}\right)$ is positive definite.

When conditions 1 and 2 are satisfied, the variance-covariance matrix $V$ of $\mathbf{u}_{t}$ is given by $V=\left(\begin{array}{cc}\frac{\sigma_{11}}{1-\mu_{11}^{2}-\sigma_{33}} & \frac{\sigma_{12}}{1-\mu_{11 \mu_{22}}} \\ \frac{\sigma_{12}}{1-\mu_{11 \mu_{22}}} & \frac{\sigma_{22}}{1-\mu_{22}^{2}-\sigma_{44}}\end{array}\right)$.

Proof to proposition 1: The starting point for the derivation of the stationarity conditions for our parameter space is the following theorem by Nicholls and Quinn (1982):

Theorem: A unique $F_{t}$-measurable stationary solution $\left\{\mathbf{u}_{t}\right\}$ exists to (9) if and only if the eigenvalues of $M$ are less than unity in modulus and the matrix $H$ given by vecH = $(I-C A)^{-1}$ vec $\Sigma_{12}$ is positive definite, where $A=(I-M \otimes M)^{-1}$ and $\Sigma_{12}$ is the covariance matrix of $\left\{e_{t}\right\}$. The covariance matrix $V$ of $\mathbf{u}_{t}$ is then given by vecV $=$ AvecH.

The first condition reduces to $\left|\mu_{11}\right|<1$ and $\left|\mu_{22}\right|<1$ given the diagonality of $M$ in our setup. Next, we derive matrix $H$ and then the conditions that ensure that it is positive definite.

As stated in the theorem matrix $H$ is given by vecH $=(I-C A)^{-1} v e c \Sigma_{12}$, with $C$ being equal to 
$C=E\left[P_{t} \otimes P_{t}\right]=E\left[\left(\begin{array}{cccc}\rho_{11 t} \rho_{11 t} & 0 & 0 & 0 \\ 0 & \rho_{11 t} \rho_{22 t} & 0 & 0 \\ 0 & 0 & \rho_{11 t} \rho_{22 t} & 0 \\ 0 & 0 & 0 & \rho_{11 t} \rho_{11 t}\end{array}\right)\right]=\left(\begin{array}{cccc}\sigma_{33} & 0 & 0 & 0 \\ 0 & 0 & 0 & 0 \\ 0 & 0 & 0 & 0 \\ 0 & 0 & 0 & \sigma_{44}\end{array}\right)$

Thus, vecH $=\left(\begin{array}{c}\sigma_{11} \frac{1-\mu_{11}^{2}}{1-\mu_{11}^{2}-\sigma_{33}} \\ \sigma_{12} \\ \sigma_{12} \\ \sigma_{22} \frac{1-\mu_{22}^{2}}{1-\mu_{22}^{2}-\sigma_{44}}\end{array}\right) \Longrightarrow H=\left(\begin{array}{cc}\sigma_{11 \frac{1-\mu_{11}^{2}}{1-\mu_{11}^{2}-\sigma_{33}}} & \sigma_{12} \\ \sigma_{12} & \sigma_{22} \frac{1-\mu_{22}^{2}}{1-\mu_{22}^{2}-\sigma_{44}}\end{array}\right)$.

Given that a symmetric matrix is positive definite if and only if all of its eigenvalues are positive, we next prove the condition based on its eigenvalues (see Judge et al. 1988, pp 960-961).

If $\sigma_{12}=0$, the eigenvalues of $H$ are $\lambda_{1}=\sigma_{11} \frac{1-\mu_{11}^{2}}{1-\mu_{11}^{2}-\sigma_{33}}$ and $\lambda_{2}=\sigma_{22} \frac{1-\mu_{22}^{2}}{1-\mu_{22}^{2}-\sigma_{44}}$. Given that $\sigma_{11}, \sigma_{22}, 1-\mu_{11}^{2}, 1-\mu_{22}^{2}$ are all positive, $H$ is positive definite $\Longleftrightarrow 1-\mu_{11}^{2}-\sigma_{33}>0$ and $1-\mu_{22}^{2}-\sigma_{44}>0$. These conditions are equivalent to the ones for scalar RC(1) models, which is natural since when $\sigma_{12}=0$, both $u_{1 t}$ and $u_{2 t}$ reduce to univariate $\mathrm{RC}(1)$ models.

Interestingly, when $\sigma_{12} \neq 0$, the conditions $1-\mu_{11}^{2}-\sigma_{33}>0$ and $1-\mu_{22}^{2}-\sigma_{44}>0$ are sufficient for the positive definiteness of $H$.

By setting $1-\mu_{11}^{2}=a, 1-\mu_{11}^{2}-\sigma_{33}=b, 1-\mu_{22}^{2}=c$ and $1-\mu_{22}^{2}-\sigma_{44}=d$, the eigenvalues of $H$ are

$$
\lambda_{1}=\frac{1}{2 b d}\left(a d \sigma_{11}+b c \sigma_{22}-\sqrt{\left(a d \sigma_{11}+b c \sigma_{22}\right)^{2}+4 b d\left(b d \sigma_{12}^{2}-a c \sigma_{11} \sigma_{12}\right)}\right)
$$

and

$$
\lambda_{2}=\frac{1}{2 b d}\left(a d \sigma_{11}+b c \sigma_{22}+\sqrt{\left(a d \sigma_{11}+b c \sigma_{22}\right)^{2}+4 b d\left(b d \sigma_{12}^{2}-a c \sigma_{11} \sigma_{12}\right)}\right) .
$$

In order to ensure that both eigenvalues are positive, it is sufficient to show that $\lambda_{1}>0$, since $\lambda_{1}<\lambda_{2}$ for all parameter values. Please note that the case of complex eigenvalues is ruled out by the symmetry of the matrix $H$ (see Lutkepohl, 1993, pp.456). The following constraints need to be taken into account: $a, b, c, d, \sigma_{11}, \sigma_{22}>0,\left|\sigma_{12}\right|<\sigma_{11},\left|\sigma_{12}\right|<\sigma_{22}, b<a$ and $d<c$. We need to show that

$$
\begin{aligned}
a d \sigma_{11}+b c \sigma_{22} & >\sqrt{\left(a d \sigma_{11}+b c \sigma_{22}\right)^{2}+4 b d\left(b d \sigma_{12}^{2}-a c \sigma_{11} \sigma_{12}\right)} \Longrightarrow \\
4 b d\left(b d \sigma_{12}^{2}-a c \sigma_{11} \sigma_{12}\right) & <0 \Longrightarrow b d \sigma_{12}^{2}-a c \sigma_{11} \sigma_{12}<0
\end{aligned}
$$

which holds for any parameter configurations subject to the constraints set earlier.

The covariance matrix $V$ of $\mathbf{u}_{t}$ is given by $v e c V=A v e c H$, so $V=\left(\begin{array}{cc}\frac{\sigma_{11}}{1-\mu_{11}^{2}-\sigma_{33}} & \frac{\sigma_{12}}{1-\mu_{11} \mu_{22}} \\ \frac{\sigma_{12}}{1-\mu_{11} \mu_{22}} & \frac{\sigma_{22}}{1-\mu_{22}^{2}-\sigma_{44}}\end{array}\right)$. 


\section{Appendix B: Nuisance parameters for the VAR(1)-RC case}

Three types of variances are associated with the process $u_{t}$ as defined by equations (4) to (6), namely the conditional or contemporaneous covariance matrix, the unconditional covariance matrix and the long-run covariance matrix. In what follows, we derive these variances for the $\operatorname{VAR}(1)-\mathrm{RC}$ case.

Conditional/contemporaneous covariance matrix:

$E\left\{\left[u_{t}-E\left(u_{t} / u_{t-1}\right)\right]\left[u_{t}-E\left(u_{t} / u_{t-1}\right)\right]^{\prime} / u_{t-1}\right\}=E\left(e_{t} e_{t}^{\prime}\right)=\Sigma_{12}$.

Unconditional covariance matrix ( $V)$ :

$$
\begin{aligned}
& V=E\left[u_{t} u_{t}^{\prime}\right]=E\left[\left(\left(M+P_{t}\right) u_{t-1}+e_{t}\right)\left(\left(M+P_{t}\right) u_{t-1}+e_{t}\right)^{\prime}\right] \Rightarrow \\
& \text { vecV }=\operatorname{vec}\left[E\left[\left(M+P_{t}\right) u_{t-1} u_{t-1}^{\prime}\left(M+P_{t}\right)^{\prime}+e_{t} e_{t}^{\prime}\right]\right] \Rightarrow \\
& \operatorname{vec} V=E\left[\left(M+P_{t}\right) \otimes\left(M+P_{t}\right) \operatorname{vec}\left(u_{t-1} u_{t-1}^{\prime}\right)+\operatorname{vec} \Sigma_{12}\right] \Rightarrow \\
& \text { vecV}=E\left[\left(M \otimes M+P_{t} \otimes P_{t}\right)\right] \operatorname{vec} V+\operatorname{vec} \Sigma_{12} \Rightarrow \\
& \text { vecV}=(M \otimes M+C) \operatorname{vec} V+\operatorname{vec} \Sigma_{12} \Rightarrow \\
& \text { vecV }-(M \otimes M+C) \operatorname{vec} V=\operatorname{vec} \Sigma_{12} \Rightarrow \\
& (I-M \otimes M-C) \text { vecV}=\operatorname{vec} \Sigma_{12} \Rightarrow
\end{aligned}
$$

$$
v e c V=(I-M \otimes M-C)^{-1} v e c \Sigma_{12} .
$$

Long-run covariance matrix $(\Omega)$ :

The long-run covariance matrix $\Omega$ can be decomposed into three matrices: the unconditional covariance matrix $V$, and two temporal matrices $\Lambda$ and $\Lambda^{\prime}$, i.e. $\Omega=V+\Lambda+\Lambda^{\prime}$, where $\Lambda=$ $E\left[T^{-1} \sum_{t=1}^{T} \sum_{s=t+1}^{T} u_{t} u_{s}^{\prime}\right]=\sum_{s=1}^{T-1} E\left(u_{t} u_{t-s}^{\prime}\right)$.

For $s=1$, we have $E\left(u_{t} u_{t-1}^{\prime}\right)=E\left[\left(\left(M+P_{t}\right) u_{t-1}+e_{t}\right) u_{t-1}^{\prime}\right]=E\left[\left(M+P_{t}\right)\right] E\left[u_{t-1} u_{t-1}^{\prime}\right]=M V$.

For $s=2$, we have $E\left(u_{t} u_{t-2}^{\prime}\right)=E\left[\left(\left(M+P_{t}\right)\left(M+P_{t-1}\right) u_{t-2}+\left(M+P_{t}\right) e_{t-1}+e_{t}\right) u_{t-2}^{\prime}\right]=$ $E\left[\left(M+P_{t}\right)\left(M+P_{t-1}\right)\right] E\left[u_{t-2} u_{t-2}^{\prime}\right]=M^{2} V$.

For $s=T-1$, we have $E\left(u_{t} u_{t-T+1}^{\prime}\right)=M^{T-1} V$.

So $\Lambda$ reduces to $\Lambda=M V+M^{2} V+\ldots+M^{T-1} V$ and given that all the eigenvalues of $M$ are less than unity in modulus, we have:

$\Lambda=M\left(I+M+M^{2}+\ldots+M^{T-2} V\right) V \rightarrow M(I-M)^{-1} V$ (where $\rightarrow$ stands for convergence as $T$ tends to infinity).

In a similar mode, $\Lambda^{\prime}=\sum_{s=1}^{T-1} E\left(u_{t-s} u_{t}^{\prime}\right)=V\left(I+M+M^{2}+\ldots+M^{T-2}\right)^{\prime} M^{\prime}=V\left(I-M^{\prime}\right)^{-1} M^{\prime}$.

Adding up the three terms we have

$\Omega=V+\Lambda+\Lambda^{\prime} \Rightarrow$

$$
\Omega=V+M(I-M)^{-1} V+V\left(I-M^{\prime}\right)^{-1} M^{\prime} .
$$

With some algebra, we relate the parameters of our DGP to the nuisance parameters, $\omega_{12} / \omega_{22}$ that describes the 'long-run correlation' effect, due to non-diagonality of the long run 
covariance matrix $\Omega=\left[\omega_{i j}\right], i, j=1,2$ and $\delta_{21}=\sum_{k=0}^{\infty} E\left(u_{20} u_{1 k}\right)$ that describes the 'endogeneity' effect. Specifically, we have:

$$
\begin{gathered}
V=\left(\begin{array}{cc}
\frac{\sigma_{11}}{1-\mu_{11}^{2}-\sigma_{33}} & \frac{\sigma_{12}}{1-\mu_{11} \mu_{22}} \\
\frac{\sigma_{12}}{1-\mu_{11} \mu_{22}} & \frac{\sigma_{22}}{1-\mu_{22}^{2}-\sigma_{44}}
\end{array}\right), \\
\Omega=V+\Lambda+\Lambda^{\prime}=\left(\begin{array}{cc}
\frac{\left(1+\mu_{11}\right) \sigma_{11}}{\left(1-\mu_{11}\right)\left(1-\mu_{11}^{2}-\sigma_{33}\right)} & \frac{\sigma_{12}}{\left(1-\mu_{11}\right)\left(1-\mu_{22}\right)} \\
\frac{\sigma_{12}}{\left(1-\mu_{11}\right)\left(1-\mu_{22}\right)} & \frac{\left(1+\mu_{22}\right) \sigma_{22}}{\left(1-\mu_{22}\right)\left(1-\mu_{22}^{2}-\sigma_{44}\right)}
\end{array}\right)
\end{gathered}
$$

and

$$
\Delta=V+\Lambda^{\prime}=\left(\begin{array}{cc}
\frac{\sigma_{11}}{\left(1-\mu_{11}\right)\left(1-\mu_{11}^{2}-\sigma_{33}\right)} & \frac{\sigma_{12}}{\left(1-\mu_{11}\right)\left(1-\mu_{11} \mu_{22}\right)} \\
\frac{\sigma_{12}}{\left(1-\mu_{22}\right)\left(1-\mu_{11} \mu_{22}\right)} & \frac{\sigma_{22}}{\left(1-\mu_{22}\right)\left(1-\mu_{22}^{2}-\sigma_{44}\right)}
\end{array}\right)
$$




\section{Appendix C: Brief description of the co-integration estimators}

We consider both parametric and semi-parametric co-integration estimators, the majority of which are asymptotically efficient provided that the conditions of the FCLT are satisfied. Next, we provide a brief description of these estimators:

Dynamic OLS (DOLS(p,t)): This estimator was suggested by Phillips and Loretan (1991), Saikonnen (1991), and Stock and Watson (1993). The term DOLS was first used by Stock and Watson who generalised it to systems with higher orders of integration. It utilises the static equation (2), augmented by lags and leads of the first difference of the regressor; that is,

$$
y_{t}=\theta x_{t}+\sum_{i=1}^{p-1} \gamma_{i} \Delta x_{t-i}+\sum_{j=1}^{t-1} d_{j} \Delta x_{t+j}+v_{t} .
$$

This model provides a direct way to estimate the co-integrating relationship and asymptotically leads to valid test statistics. When there are no feedbacks from the co-integration error to the error that drives the regressor, it is sufficient to augment the co-integration estimator (2) only by lags of $\Delta x_{t}$. Any serial correlation of $v_{t}$ does not raise any serious problems in the estimation of $\theta$ and can be dealt with by consistently estimating the long-run variance of $v_{t}$ as proposed by Newey and West (1987).

Fully Modified Least Squares (FMLS): Phillips and Hansen (1990) employ semi-parametric corrections for the long-run correlation and endogeneity effects, which fully modify the OLS estimator and its attendant standard error, thus obtaining the so-called FMLS estimation method. The FMLS estimator is based on consistent estimation of the $\Omega$ and $\Delta$ matrices, which in turn requires the selection of a kernel and the determination of the bandwidth. We employ the quadratic spectral kernel, since it is optimal with respect to an asymptotic truncated mean square error criterion in the class of kernels that necessarily generate positive semi-definite estimators of the long-run variance covariance matrix in finite samples. The bandwidth parameter has been selected by applying either the Newey-West (1994) or the Andrews (1991) procedure. Moreover, we consider the 'pre-whitened' version of FMLS which filters the error vector $\widehat{\mathbf{u}}_{t}$ prior to estimating $\Omega$ and $\Delta$ (see Andrews and Monahan, 1992; Christou and Pittis, 2002; and Panopoulou and Pittis, 2004, for a discussion on the performance of the various versions of the FMLS estimator).

Canonical Co-integrating Regression (CCR): Park's (1992) CCR is closely related to FMLS, but instead employs stationary transformations of the data to obtain least squares estimates to remove the long-run dependence between the co-integrating equation and stochastic regressors innovations. As in FMLS, the first step in CCR is to obtain estimates of the innovations $\mathbf{u}_{t}$ and corresponding consistent estimates of the long-run covariance matrices $\Omega$ and $\Lambda$. Similarly to FMLS, we consider the pre-whitened version of CCR and employ the quadratic spectral kernel, while we apply either the Newey-West or the Andrews procedure for bandwidth selection.

Johansen's Maximum Likelihood (JOH): Apart from various single-equation estimators, we also consider the system-based maximum likelihood estimator of $\theta$, suggested by Johansen 
$(1988,1991)$. The order of the JOH estimator corresponds to the lag-order of the VAR model on which this estimator is based. An important difference of this estimator from the other cointegration estimators considered in this study is that it has been developed and proved to be asymptotically optimal in the context of a Gaussian vector autoregression which accommodates a rather narrow class of DGPs.

Augmented Autoregressive Distributed Lag (AADL(q,r,s)): This estimator is based on the following ADL(q,r) model (see Pesaran and Shin, 1999):

$$
y_{t}=\sum_{i=0}^{q} a_{i} x_{t-i}+\sum_{j=1}^{r} b_{j} y_{t-j}+\nu_{t}
$$

The parameter of interest is equal to the long-run multiplier of $y_{t}$ with respect to $x_{t}$. A direct estimate of the parameter of interest $\theta$ along with its standard error may be obtained by transforming the ADL model into the Bewley form (see Bewley, 1979; Wickens and Breusch, 1988; Banerjee et al., 1993):

$$
y_{t}=\theta x_{t}+\sum_{i=1}^{q-1} a_{i} \Delta x_{t-i}+\sum_{j=1}^{r-1} b_{j} \Delta y_{t-j}+\epsilon_{t} .
$$

Estimates of the coefficients and their standard errors can be obtained by using the instrumental variables (IV) estimator, with the original matrix of regressors being the IV (see Wickens and Breusch, 1988). This means that the ADL estimator of $\theta$ is very easy to apply since it involves only IV estimation techniques. The AADL estimator is an extension of the ADL estimator where leads of the regressor are added to the equation. Specifically, the AADL estimator of $\theta$ is calculated based on the following equation:

$$
y_{t}=\theta x_{t}+\sum_{i=1}^{q-1} a_{i} \Delta x_{t-i}+\sum_{j=1}^{r-1} b_{j} \Delta y_{t-j}+\sum_{h=1}^{s-1} a_{h} \Delta x_{t+h}+\epsilon_{t} .
$$

AADL is required when there is Granger causality running from the co-integrating error to the error that drives the regressor. In such a case, augmentation of the ADL model by the leads of the regressor restores super-exogeneity and removes the second-order asymptotic biases, thus rendering the AADL estimator asymptotically efficient. 


\section{Appendix D: Tests for parameter instability in the co-integrating equation}

We employ Hansen's (1992) tests for parameter instability in co-integrating regressions, which can be derived as Langrange multiplier (LM) tests in correctly specified likelihood problems. The three tests, namely, $L_{c}, M e a n F$, and $S u p F$ are all tests of the same null hypothesis but differ in their choice of alternative. The null hypothesis is that the co-integrating vector is timeinvariant (constant), while the alternative is that parameters either follow a martingale process $\left(L_{c}, M e a n F\right)$ or exhibit a single structural break at unknown time $t$ (SupF). The tests are built in the context of fully modified estimation of the co-integrated regression. To save space, we do not give details on the formulation of the tests. However, all tests tend to have power in similar directions and can detect whether the proposed model is a good model that captures a stable relationship. The asymptotic distribution of the test statistics is non-standard and depends on the nature of trends in the co-integrating regression. Hansen (1992) provides both tabulated critical values and function $p$-values that map the observed test statistic into the appropriate value in the range of $[0,1]$ and more specifically into the range of interest $[0,0.20]$.

Table D1 presents the stability tests for the parameters in the co-integrating regression (Equation 1) for the countries under scrutiny. Test statistics are calculated on the basis of fully modified estimation with the covariance parameters estimated using the quadratic spectral kernel and pre-whitened residuals with a VAR(1) model. The bandwidth is selected by means of the Andrews (1991) procedure. $P$-values are calculated by the function $p$-value methodology (see Hansen, 1992). A $p$-value of 0.20 suggests significance at the $>0.20$ level. The Gauss code employed is available on the website of Professor Bruce E. Hansen.

Overall, our findings suggest that the co-integrating relationship between inflation and interest rates is stable. More specifically, on the grounds of the $L_{c}$ test and a $5 \%$ significance level, we cannot reject the null of stability for all the countries at hand with the exception of Austria. Similarly, the MeanF test points to stability of the co-integrating relationship for the majority of the countries with the exception of Austria, Italy, Portugal, and Switzerland. Turning to the SupF test, our results point to weaker evidence with respect to stability of the co-integration vector, as the null is rejected for six countries, namely, Austria, Denmark, France, Italy, Portugal, and Switzerland. A word of caution is in order here; rejection of the null does not imply that the particular alternative that a test is designed to detect holds, as there are many possibilities behind this outcome. Taking this and our stability test results into account, we conjecture that our choice to model the co-integrating relationship as stable and allow for time-varying dynamics in the error generating process is justified by our long-run dataset. 
Table D1. Parameter stability tests

\begin{tabular}{lcccccc}
\hline \hline Country /Test & $L_{c}$ & $($ p-val $)$ & MeanF & $($ p-val $)$ & SupF & $(p$-val $)$ \\
\hline Australia & 0.098 & $(0.200)$ & 1.673 & $(0.200)$ & 4.312 & $(0.200)$ \\
Austria & 15.061 & $(0.010)$ & 94.276 & $(0.010)$ & 191.814 & $(0.010)$ \\
Belgium & 0.179 & $(0.200)$ & 1.944 & $(0.200)$ & 7.491 & $(0.200)$ \\
Canada & 0.136 & $(0.200)$ & 1.300 & $(0.200)$ & 9.971 & $(0.156)$ \\
Denmark & 0.126 & $(0.200)$ & 3.982 & $(0.083)$ & 16.955 & $(0.010)$ \\
France & 0.236 & $(0.200)$ & 2.979 & $(0.176)$ & 7.704 & $(0.010)$ \\
Germany & 0.275 & $(0.176)$ & 1.863 & $(0.200)$ & 3.688 & $(0.200)$ \\
Italy & 0.222 & $(0.200)$ & 8.425 & $(0.010)$ & 19.765 & $(0.010)$ \\
Ireland & 0.183 & $(0.200)$ & 1.992 & $(0.200)$ & 7.707 & $(0.200)$ \\
Japan & 0.205 & $(0.200)$ & 2.132 & $(0.200)$ & 7.074 & $(0.200)$ \\
Luxembourg & 0.145 & $(0.200)$ & 1.352 & $(0.200)$ & 6.681 & $(0.200)$ \\
Netherlands & 0.294 & $(0.155)$ & 1.781 & $(0.200)$ & 6.107 & $(0.200)$ \\
New Zealand & 0.091 & $(0.200)$ & 1.295 & $(0.200)$ & 4.223 & $(0.200)$ \\
Norway & 0.203 & $(0.200)$ & 2.665 & $(0.200)$ & 8.971 & $(0.200)$ \\
Portugal & 0.280 & $(0.170)$ & 52.352 & $(0.010)$ & 170.50 & $(0.010)$ \\
Sweden & 0.088 & $(0.200)$ & 1.690 & $(0.200)$ & 11.316 & $(0.093)$ \\
Switzerland & 0.393 & $(0.081)$ & 6.215 & $(0.015)$ & 25.930 & $(0.010)$ \\
UK & 0.179 & $(0.200)$ & 3.922 & $(0.085)$ & 7.565 & $(0.200)$ \\
USA & 0.244 & $(0.200)$ & 3.150 & $(0.158)$ & 10.394 & $(0.108)$ \\
\hline \hline
\end{tabular}




\section{Appendix E: Sensitivity of co-integration tests to time-varying dynamics}

We conduct a simple Monte Carlo experiment to investigate the behaviour of the trace statistic and the maximum-eigenvalue statistic developed by Johansen $(1988,1991)$ and Johansen and Juselius (1990) in the context of DGPs with time-varying dynamics. We first examine various DGPs with a break in the co-integrating parameter, while the error of the co-integrating equation and the error that drives the regressor follow a $\operatorname{VAR}(1)$ process. We consider four different pairs of values for $\theta$, taken randomly from the real data estimations of Haug et al. (2011). The cases considered range from DGPs with a small change in $\theta$ to DGPs with rather large changes in the value of $\theta$. We assume that the break in $\theta$ happens at $r T$ where $T$ is the sample size and $r=0.3,0.5$, and 0.7 . We use 2000 replications and we consider sample sizes of $T+50$ observations with $T$ equal to 50,150 , and 200 . In all cases, the first 50 observations are discarded to eliminate the effect of initial values. Panel A of Table E1 reports the percentage of times each co-integration test suggests the existence of co-integration. In general, both statistics behave in a similar manner. They both rarely indicate the existence of co-integration especially for large breaks in the value of $\theta$. For example, when $\theta$ increases from 0.69 to 1.64, the trace statistic finds co-integration in less than $18 \%$ of the cases (in most cases, this figure is below $10 \%$ ) for all sample sizes and all values of $r$ considered in our simulation. It is interesting to note that as $r$ increases, both co-integration tests indicate the existence of co-integration less often. In all the cases reported in Panel A of Table E1, $\theta$ increases after the break-point. For completeness, we also considered the opposite case. The results are not reported for brevity, since they are qualitatively similar.

We next repeat the same procedure in the context of DGPs with a constant $\theta$ and timevarying dynamics in the error terms. To be more specific, we consider DGPs 1-3 and 7-9 from our first Monte Carlo experiment described in Section 2.4. Once again, 2000 random samples of size $T+50$ are generated for each DGP, where $T=50,150$, and 200, and the first 50 observations are discarded to remove the effect of initial values. The results are reported in Panel B of Table E1. It turns out that the power of both co-integration tests increases substantially, especially for large sample sizes. When $T=150$ or 200 , both tests indicate the existence of co-integration in more than $80 \%$ of the cases for almost all specifications. In summary, our findings suggest that the existence of a break in the co-integrating parameter $\theta$ makes both co-integration tests frequently reject co-integration, especially when the break in $\theta$ is large. On the other hand, in the context of DGPs considered in this study (i.e. DGPs with constant $\theta$ and time-varying dynamics in the process that describes the co-integrating error and the error that drives the regressor), co-integration tests have significant power in finding co-integration. We should note however that our simulation experiment is not extensive and, similarly to all Monte Carlo experiments, the findings apply to the DGPs and sample sizes considered in the analysis. 
Table E1. Co-integration tests and time-varying dynamics

\begin{tabular}{|c|c|c|c|c|c|c|c|}
\hline \multicolumn{8}{|c|}{ Panel A: DGPs with a break in the co-integration parameter $\theta$} \\
\hline \multicolumn{2}{|l|}{$\mathrm{T}=50$} & \multicolumn{2}{|c|}{ Breakpoint $=0.3$} & \multicolumn{2}{|c|}{ Breakpoint $=0.5$} & \multicolumn{2}{|c|}{ Breakpoint $=0.7$} \\
\hline$\theta_{1}$ & $\theta_{2}$ & Trace & Max-Eig. & Trace & Max-Eig. & Trace & Max-Eig \\
\hline 0.940 & 1.270 & 0.328 & 0.351 & 0.280 & 0.305 & 0.257 & 0.302 \\
\hline 0.630 & 1.350 & 0.169 & 0.184 & 0.121 & 0.152 & 0.125 & 0.160 \\
\hline 0.690 & 1.640 & 0.177 & 0.181 & 0.104 & 0.121 & 0.090 & 0.112 \\
\hline 0.930 & 2.150 & 0.135 & 0.149 & 0.082 & 0.105 & 0.086 & 0.114 \\
\hline \multicolumn{2}{|l|}{$\mathrm{T}=150$} & \multicolumn{2}{|c|}{ Breakpoint $=0.3$} & \multicolumn{2}{|c|}{ Breakpoint $=0.5$} & \multicolumn{2}{|c|}{ Breakpoint $=0.7$} \\
\hline$\theta_{1}$ & $\theta_{2}$ & Trace & Max-Eig. & Trace & Max-Eig. & Trace & Max-Eig \\
\hline 0.940 & 1.270 & 0.535 & 0.549 & 0.395 & 0.436 & 0.353 & 0.399 \\
\hline 0.630 & 1.350 & 0.224 & 0.227 & 0.107 & 0.135 & 0.104 & 0.129 \\
\hline 0.690 & 1.640 & 0.156 & 0.160 & 0.066 & 0.076 & 0.076 & 0.088 \\
\hline 0.930 & 2.150 & 0.129 & 0.139 & 0.062 & 0.076 & 0.054 & 0.066 \\
\hline \multicolumn{2}{|l|}{$\mathrm{T}=200$} & \multicolumn{2}{|c|}{ Breakpoint $=0.3$} & \multicolumn{2}{|c|}{ Breakpoint $=0.5$} & \multicolumn{2}{|c|}{ Breakpoint $=0.7$} \\
\hline$\theta_{1}$ & $\theta_{2}$ & Trace & Max-Eig. & Trace & Max-Eig. & Trace & Max-Eig \\
\hline 0.940 & 1.270 & 0.572 & 0.597 & 0.412 & 0.456 & 0.371 & 0.401 \\
\hline 0.630 & 1.350 & 0.235 & 0.259 & 0.119 & 0.147 & 0.108 & 0.131 \\
\hline 0.690 & 1.640 & 0.179 & 0.188 & 0.070 & 0.089 & 0.074 & 0.097 \\
\hline 0.930 & 2.150 & 0.128 & 0.145 & 0.055 & 0.069 & 0.055 & 0.068 \\
\hline \multicolumn{8}{|c|}{ Panel B: DGPs with constant $\theta$ and time-varying dynamics in the errors } \\
\hline & & $\mathrm{T}=50$ & & $\mathrm{~T}=150$ & & $\mathrm{~T}=200$ & \\
\hline & & Trace & Max-Eig. & Trace & Max-Eig. & Trace & Max-Eig \\
\hline DGP-1 & & 0.700 & 0.730 & 0.927 & 0.933 & 0.947 & 0.947 \\
\hline DGP-2 & & 0.805 & 0.828 & 0.947 & 0.949 & 0.949 & 0.949 \\
\hline DGP-3 & & 0.327 & 0.341 & 0.677 & 0.722 & 0.891 & 0.913 \\
\hline DGP-7 & & 0.554 & 0.578 & 0.803 & 0.825 & 0.907 & 0.915 \\
\hline DGP-8 & & 0.376 & 0.397 & 0.693 & 0.731 & 0.884 & 0.902 \\
\hline DGP-9 & & 0.557 & 0.572 & 0.800 & 0.827 & 0.915 & 0.923 \\
\hline
\end{tabular}

